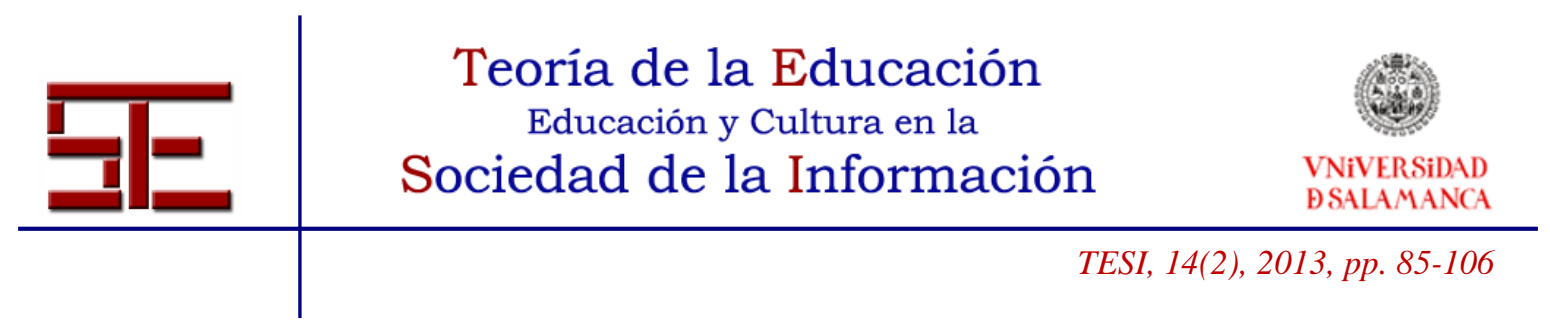

\title{
LA BÚSQUEDA Y SELECCIÓN DE LA INFORMACIÓN ONLINE: ANÁLISIS DE LAS ACCIONES ESTRATÉGICAS DE LOS ESTUDIANTES UNIVERSITARIOS
}

Resumen: Como actividad compleja y dinámica, la búsqueda y selección de información online precisa del desempeño estratégico para conseguir procesos y resultados eficaces y significativos. El objetivo de este trabajo es analizar si los estudiantes universitarios perciben o no que deben ser estratégicos, para qué acciones, en qué momentos, y qué tipo de valoración realizan sobre las acciones estratégicas más relevantes en el proceso de búsqueda y selección de información en Internet. Los resultados muestran diferencias entre los estudiantes según el curso, siendo los de los últimos cursos, que además han recibido formación, los que mejor predisposición muestran hacia las acciones estratégicas. También se han encontrado dos factores que explican esta predisposición en términos de acciones básicas y acciones complementarias.

Palabras clave: Búsqueda de información; Estrategias; Educación Superior.

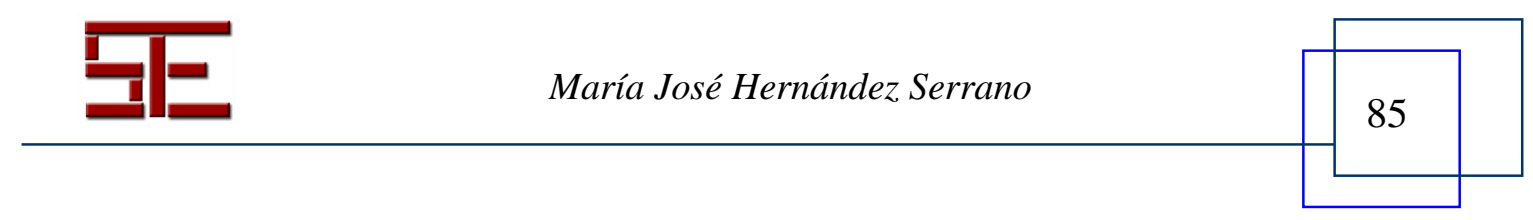




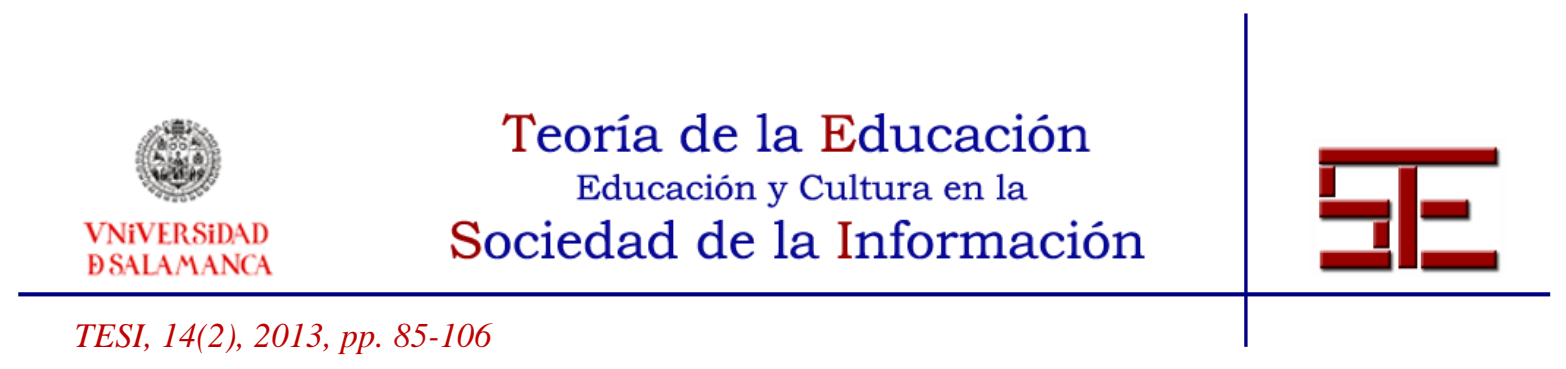

\title{
SEARCHING AND SELECTING ONLINE INFORMATION: ANALYSIS OF THE STRATEGIC ACTIONS OF THE UNIVERSITY STUDENTS
}

\begin{abstract}
As complex and dynamic activity, the searching and selection of online information needs a strategic performance in order to achieve effective and meaningful results and processes. The aim of this paper is to analyze whether university students perceive a need to be strategic, for what actions, what times, and what are their predispositions towards the strategic actions in the Internet information searching and selection process. Results showed differences between students by course, those in their final courses, who have also received training, showed better predisposition to strategic actions. Two factors that explain the university students' predispositions were found, in terms of basic actions and complementary actions.
\end{abstract}

Key words: Internet information searching; Strategies; Higher education.

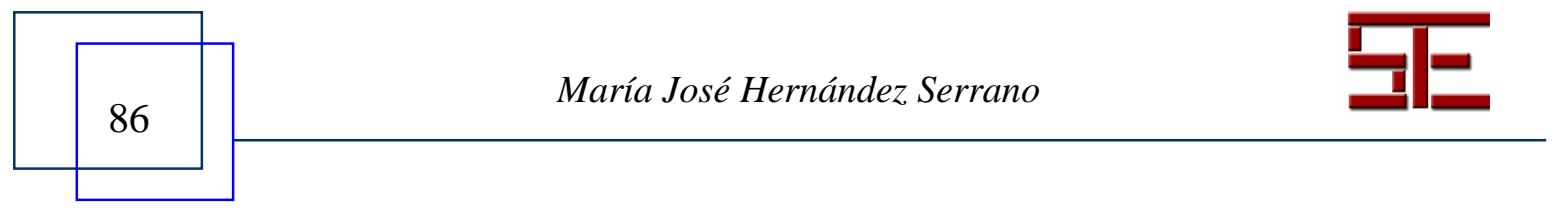




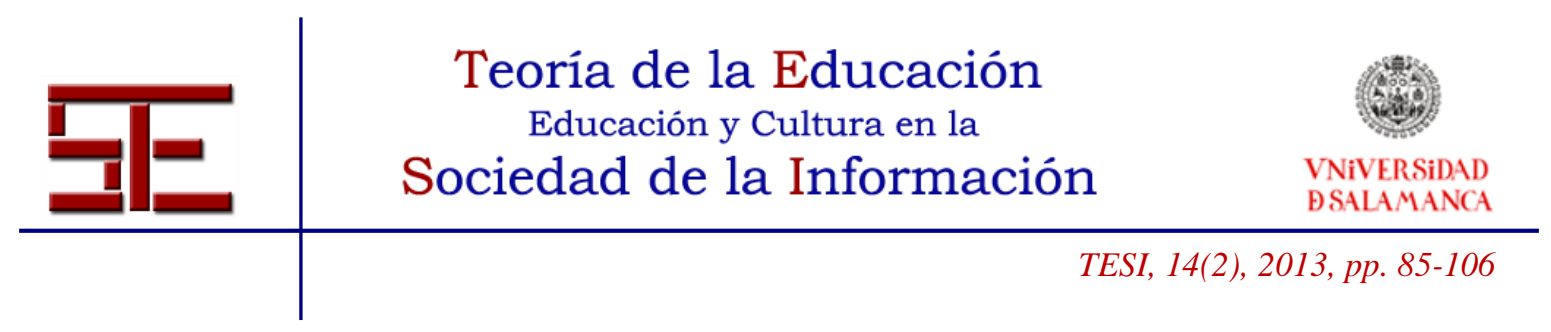

\section{LA BÚSQUEDA Y SELECCIÓN DE LA INFORMACIÓN ONLINE: ANÁLISIS DE LAS ACCIONES ESTRATÉGICAS DE LOS ESTUDIANTES UNIVERSITARIOS}

Fecha de recepción: 05/03/2013; fecha de aceptación: 19/07/2013; fecha de publicación: 30/07/2013

María José Hernández Serrano

mjhs@usal.es

Universidad de Salamanca

\section{1.- BUSCAR Y ENCONTRAR INFORMACIÓN COMO ACTIVIDAD ESTRATÉGICA}

Hace más de una década argumentaba Edgar Morin (2001) que uno de los desafíos más difíciles del nuevo milenio tendría que ver con la modificación de nuestro pensamiento de manera que pudiera hacer frente a la complejidad creciente, a la rapidez de los cambios y a lo imprevisible. Hoy vivimos ya en contextos cambiantes e inciertos. Describe Innerarity (2011) nuestra sociedad actual, la sociedad de la información y el conocimiento, como un terreno de certezas escasas, discusión, riesgo y necesaria creatividad.

Sabemos que la complejidad multiplica el número de retos y, aunque se le pida, desde la educación sigue siendo difícil pronosticar respuestas ante los retos derivados de la sociedad actual. Quizás, por ello, seguimos planteándonos los mismos interrogantes que hace una década respecto a las competencias necesarias para desenvolverse y aprender. No es fácil determinar qué debe saber un alumno frente a un contexto cambiante, y puede que la tendencia contemporánea de rescatar habilidades globales y transversales en su aplicación, sea una opción viable. En esa línea, cuando Morin se preguntaba por los "saberes fundamentales para la educación del futuro", ya entre ellos situaba los principios de acción estratégica. Estos principios no son más que ayudas necesarias para afrontar los riesgos, lo inesperado, la incipiente complejidad. Principios, que no ofrecen respuestas innovadoras, sino formas diferentes de afrontar la misma realidad, es decir, formas de entender la acción de manera planificada, consciente y reflexiva.

Reconocidos en la jerarquía de importancia que hoy merecen, estos principios estratégicos deben convertirse en pilares esenciales de las "sociedades cambiantes". Y, concretamente, cuando pensamos en actividades de cierta complejidad, como la búsqueda y selección de información online, estos principios y acciones estratégicas se hacen imprescindibles. Veamos.

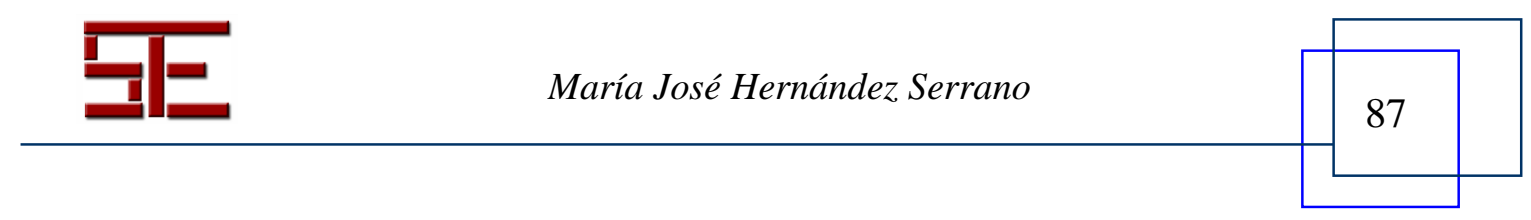




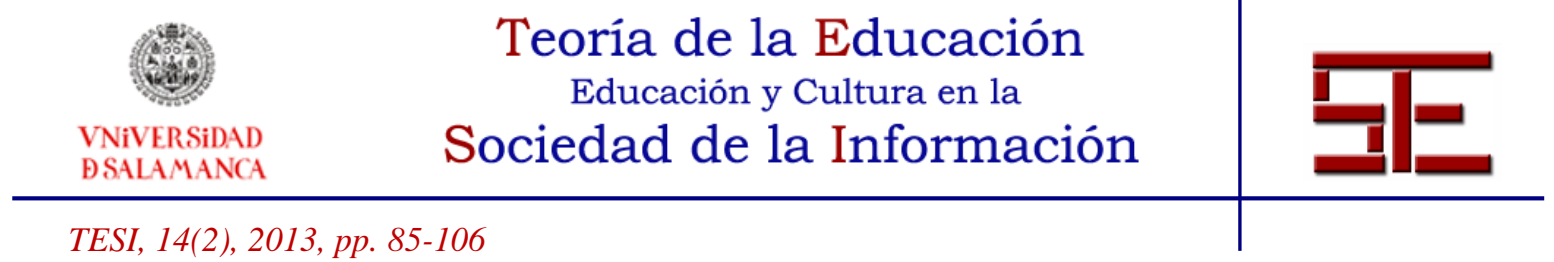

Aunque es una de las actividades más frecuentes de entre las múltiples que se puede llevar a cabo de forma mediada por las TIC, buscar información en Internet no siempre se corresponde con encontrar una respuesta sencilla, confirmar un dato o acceder al recurso esperado; en muchas ocasiones, esta actividad enfrenta al sujeto a retos inesperados e inciertos, y en definitiva mediana o altamente complejos.

El hecho de interpretar la actividad de búsqueda como un contexto complejo se debe fundamentalmente a las características del medio Internet, que es en sí un entorno abierto y desordenado, donde la variedad de fuentes y recursos informativos puede resultar abrumadora (Jones y Goff, 2011). La actividad, por tanto, ya se desarrolla en un entorno complejo, pero, además, no todas las actividades de búsqueda son iguales, en cuanto al contenido o al proceso a seguir; aun empleando siempre los mismos recursos de acceso a la información, la selección hasta encontrar información relevante o de calidad puede volverse una tarea incierta, una complicada toma de decisiones (Pharo, 2004; Salden, Pass y Van Merriënboer, 2006) y, dependiendo de la información, una actividad larga y tediosa, teniendo que separar y cribar lo que realmente es valioso.

Los inconvenientes que estamos destacando se corresponden ni más ni menos que con algunas de las condiciones señaladas en la literatura específica sobre estrategias, y estrategias de aprendizaje, como requisitos para el desempeño estratégico. Cuando una acción no puede resolver de manera rutinaria, heurística o informal, sino que se hace preciso que la toma de decisiones sea estratégicamente deliberada y supervisada, entran en juego diversos condicionantes. De todos los condicionantes posibles destacamos los dos más relevantes para el contexto de la búsqueda de información online. El primero hace referencia al hecho de que existan opciones alternativas de acción (Boekaerts, 1999; Gargallo, 2000) y el segundo a la necesidad de que se tenga que ejercer un control consciente sobre la toma de decisiones (Nisbet y Shucksmith, 1993; Monereo y Castelló, 1997).

Sobre el primero, no hace falta especificar que las alternativas de acción cuando se busca son ilimitadas; aun entendiendo que mayoritariamente se empieza a buscar desde el mismo recurso -incluso la propia actividad ya se denomina así: Googlear, o Googling, como verbo en el ámbito anglosajón-, las formas de buscar y las distintas palabras que se empleen conducen a caminos y alternativas de resolución diferentes.

Sobre el segundo, para que pueda ejercerse un control consciente de la actividad, ésta debe ser intencional y estar orientada a una meta; en el caso de la búsqueda y selección, la meta a establecer se corresponde con el tipo, la cantidad y la calidad de la información que se desea hallar. De esta manera, si pienso en lo que busco, cuando selecciono pondré atención en lo que considero relevante, en el grado de rigor y en la utilidad que merece la

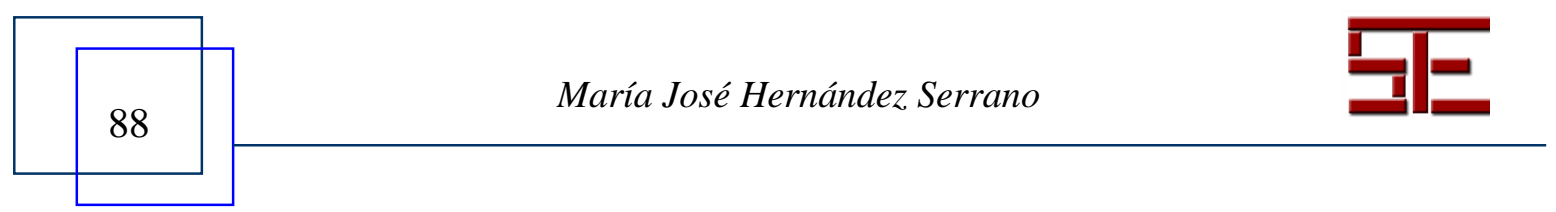




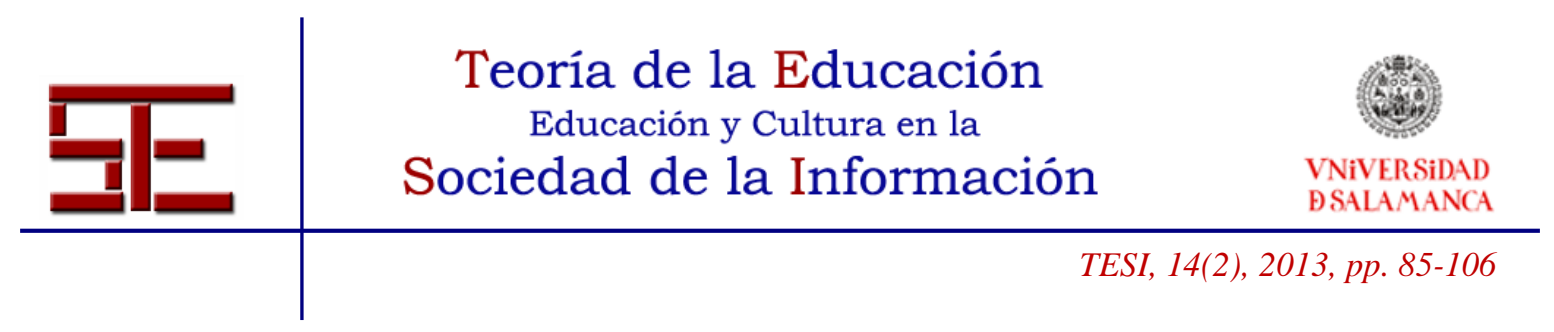

información hallada, lo que me dará pie a reflexionar sobre nuevas búsquedas, más precisas, más ajustadas de acuerdo a la información que voy encontrando.

Es preciso aclarar que, aunque el establecimiento de metas y la planificación inicial de la búsqueda sean actividades clave, cuando decimos que se necesitan estrategias para buscar, para seleccionar y para usar la información hallada estamos diciendo que se necesita ser estratégico durante todo el proceso. Primero, prestando atención a aquello que se quiere encontrar para pensar y planificar cómo buscar; después, recordando esa meta para saber cómo seleccionar y evaluar; y, finalmente, aprendiendo del proceso para extrapolar acciones estratégicas útiles para nuevas búsquedas. De manera resumida nos estamos refiriendo a tres etapas: antes, durante y después.

En estas tres etapas las acciones estratégicas que tienen que ver con la planificación, la consciencia/reflexión, la atención, la regulación y la supervisión/evaluación se convierten en actividades necesarias para la efectividad de la búsqueda y localización de información online. Pero no sólo efectividad, sino también significatividad, especialmente si se trabaja en contextos donde la localización de información se corresponde con un ejercicio de investigación personal para resolver una tarea académica y/o aprender sobre un tema.

Es precisamente en este ámbito académico donde tiene sentido aplicar acciones estratégicas a la localización de información. Cuando se pide a los estudiantes buscar información en Internet no es para que resuelvan una tarea de manera repetitiva, consultando una única fuente, sin contrastar la información, sin realizar una evaluación crítica..., sino para que planifiquen, controlen y reflexionen sobre el proceso. Y por supuesto no, o no sólo, para que encuentren una información correcta, sino para que generen conocimiento a partir de esa información hallada (Hernández-Serrano, 2009).

Ahora bien, el reto al que nos enfrentamos, y objeto de estudio de este trabajo, es si los estudiantes identifican la búsqueda y localización de información como una actividad estratégica. Hasta qué punto los estudiantes perciben que buscar y seleccionar información en Internet es una tarea compleja, que necesita del establecimiento de una meta, y donde es preciso llevar a cabo una toma de decisiones consciente. $\mathrm{O}$ si perciben que, por el contrario, el medio informacional siempre les devolverá las respuestas correctas, de manera sencilla y rápida, sin necesidad de pensar cómo llevar a cabo el proceso o qué características mínimas debe tener la información localizada.

Los estudios llevados a cabo en el ámbito académico han confirmado, por un lado, que los estudiantes confían excesivamente en las posibilidades del medio informacional, y muestra de ello son las actitudes altamente positivas que mantienen hacia Internet como un medio accesible, con información diversa, y que les resuelve sus necesidades

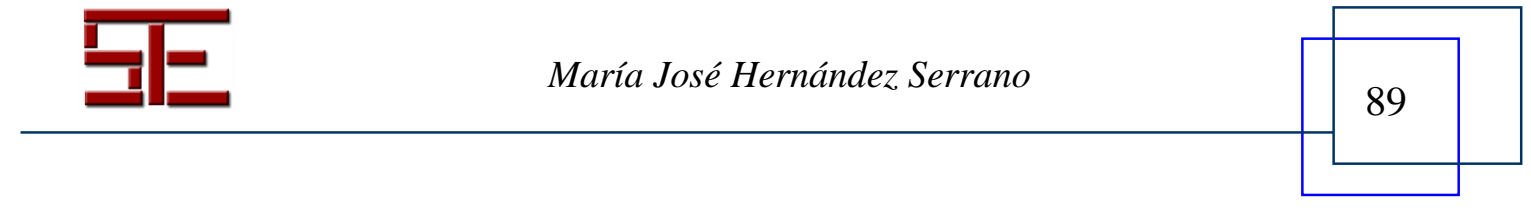




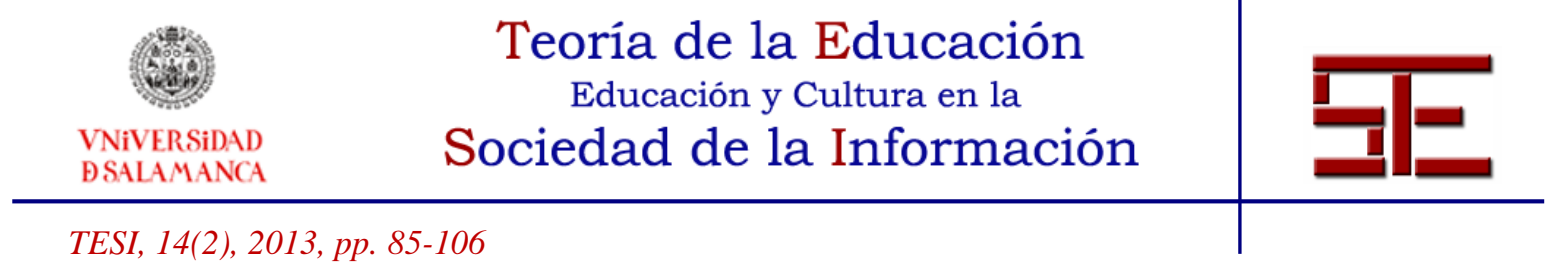

informativas con rapidez (Liaw et al., 2006; Chung y Newman, 2007). Esto se traduce en que para ellos no es necesario ejercer un desempeño estratégico, ya que supuestamente el medio les ofrecerá la mejor respuesta. Incluso, cuanto más jóvenes son los estudiantes más confiados se muestran hacia las posibilidades del medio informacional y más seguros se sienten de que obtendrán éxito (Hernández, Jones y González, 2011). Por otro lado, entre los estudios que han abordado la formación de usuarios de información y la alfabetización informacional (ALFIN), se comprueba que dicha formación se ha centrado en habilidades específicas para las diferentes fases de búsqueda, pero no en la visión global del proceso, donde las fases están interconectadas. Hughes (2009) ha señalado que debido a la importancia adquirida por la ALFIN en los últimos años, los estudiantes están adquiriendo habilidades de búsqueda de información, pero no habilidades estratégicas. El interés por introducir métodos estratégicos en la actividad de búsqueda y selección de información en Internet ha sido abordado por diferentes investigadores, tanto en contextos académicos universitarios como preuniversitarios (Xie y Joo, 2010; Yuan y Belkin, 2010; Hernández, 2009; Tu, Shih y Tsai, 2008; Winsler, Naglieri y Manfra, 2006; Monereo y Fuentes, 2005), incluso se ha elaborado una propuesta de inventario de estrategias (Tsai, 2009). Teniendo como referencia estos trabajos, presentamos los resultados de nuestro estudio sobre la predisposición estratégica de los estudiantes universitarios.

Este artículo tiene un objetivo principal que es describir las acciones que realizan o consideran útiles realizar los estudiantes universitarios antes de buscar y durante la búsqueda y selección de información online. Además, como meta analítica más específica, se pretenden categorizar las predisposiciones en base a un modelo de siete acciones estratégicas necesarias para el éxito del proceso, tratando de verificar cuáles identificarían los estudiantes como actividades básicas o primarias y cuáles serían complementarias o de segundo orden.

\section{2.- DISEÑO DEL ESTUDIO}

\section{1.- Muestra}

Para el estudio se seleccionó una muestra de 60 estudiantes universitarios de la Facultad de Educación de la Universidad de Salamanca, de diferentes cursos y ciclos, con garantías de proporcionalidad respecto a la población original. La muestra estuvo compuesta por 32 sujetos de $1^{\circ}$ ciclo y 28 de $2^{\circ}$ ciclo, de edades comprendidas entre los 18 y los 22 años, siendo el $92 \%$ mujeres. Menos de un tercio de los sujetos afirmó que había recibido

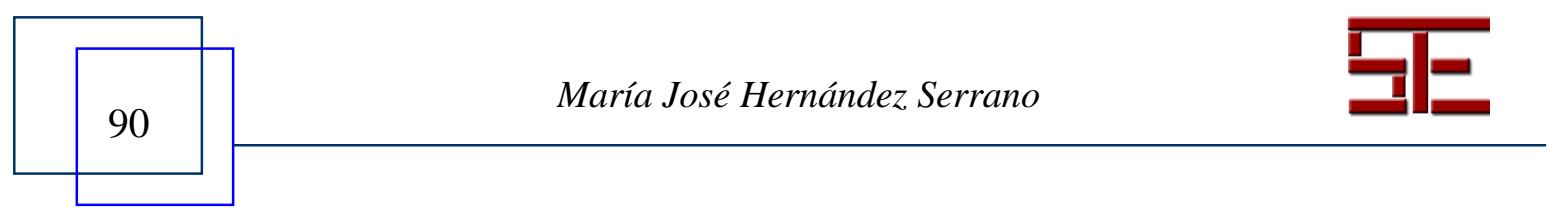




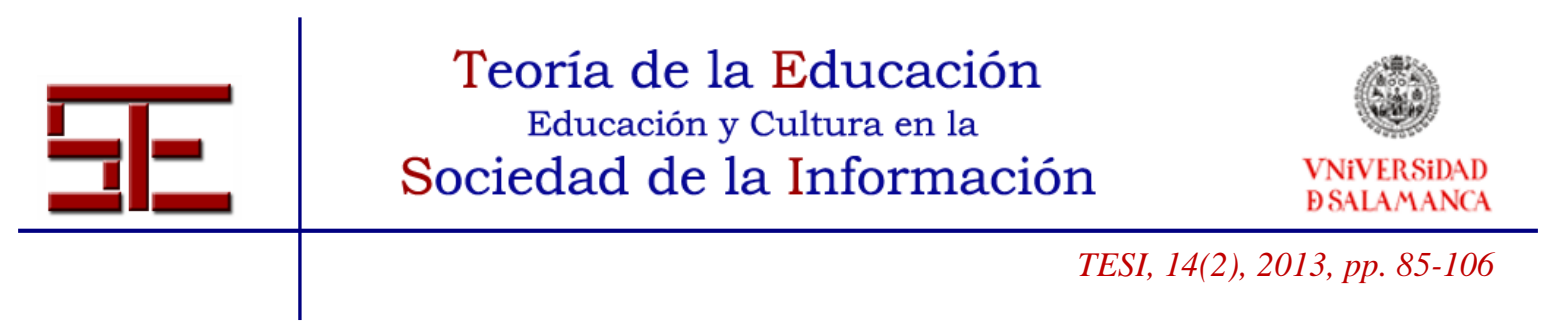

formación en una asignatura de la carrera sobre cómo buscar información online; el porcentaje restante afirmó que habían aprendido a buscar información por sí mismos.

\section{2. - Método e instrumento}

Con el objetivo de analizar las actitudes de los estudiantes hacia el uso de procedimientos estratégicos se administró un cuestionario ad hoc sobre la valoración de las acciones implicadas en las diferentes fases del proceso de búsqueda: antes, durante y después. Este cuestionario se elaboró a partir de un análisis de las diferentes fases ${ }^{1}$, junto con las acciones más significativas y mayormente citadas en la literatura específica, como propias de cada fase. Los datos analizados en este trabajo se refieren concretamente a la predisposición de los estudiantes hacia el desarrollo de diversas acciones llevadas a cabo antes de buscar y durante la búsqueda.

Para el análisis de la primera fase, antes de buscar, se seleccionaron cuatro acciones sobre la planificación del proceso, principalmente relacionadas con la delimitación del tema y con la preparación de los recursos necesarios. A los estudiantes se les pidió que seleccionaran cuáles de estas actividades realizaban y/o cuáles de ellas recomendarían realizar a una persona que empezara a buscar. Combinando ambas categorías, se obtuvieron cuatro tipos de valoraciones: eficaz (si realiza y recomienda realizar); ineficaz (si no realiza ni recomienda); útil (no realiza pero recomienda); e inútil (no realiza ni recomienda).

Para el análisis de la segunda fase, durante la búsqueda, se distinguieron tres tipos de acciones: el método preferente para iniciar la búsqueda (valorando la mayor o menor

\footnotetext{
${ }^{1}$ Referimos a otros trabajos previos (Hernández, 2009; Hernández y Fuentes, 2011) donde se realizó una análisis de las distintas fases que, de acuerdo a diversos ámbitos y disciplinas científicas, comprende el proceso informacional, hallándose ocho: (1) la formulación de la demanda, (2) la elección de la fuente de información, (3) el acceso a la información, (4) la selección de la información, (5) la evaluación de la información que se encuentra, (6) la planificación del uso de la información teniendo en cuenta los aspectos éticos, (7) el procesamiento de la información y (8) otras habilidades relacionadas con el aprendizaje permanente. De manera resumida nos estamos refiriendo a tres etapas: antes (1 y 2), durante $(3,4$ y 5$)$ y después del proceso $(6,7$ y 8$)$.
}

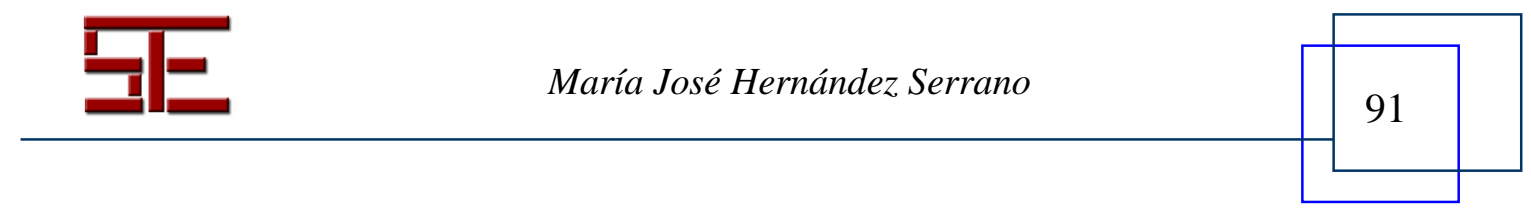




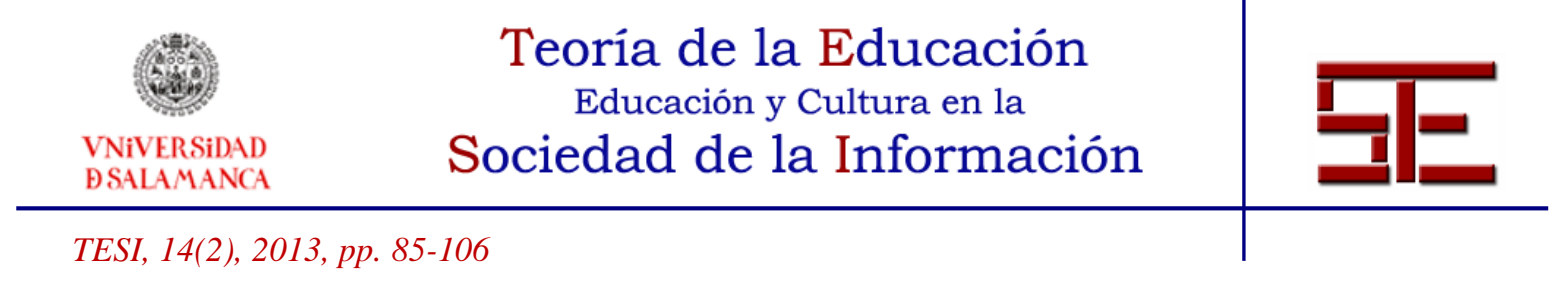

frecuencia para iniciar las búsquedas de acuerdo a cinco métodos diferentes); las actividades para seguir buscando (analizando la toma de decisiones respecto a cuatro actividades, y su frecuencia de realización); y las razones para terminar una búsqueda (a través de seis razones, más una opción alternativa de respuesta abierta).

Finalmente, se elaboró un modelo de siete acciones estratégicas necesarias para el éxito del proceso (ver Figura 1), pidiendo a los estudiantes que valoraran en una escala tipo Likert (1-5; nada-mucho) la importancia que les merecía cada una de las acciones. Además del análisis de las frecuencias y los estadísticos descriptivos se realizó un análisis de componentes principales, para comprobar si la frecuencia hallada en las siete acciones se podría agrupar en un número menor de factores basados en las etapas del proceso, o bien factores de relevancia en cuanto a la predisposición estratégica.

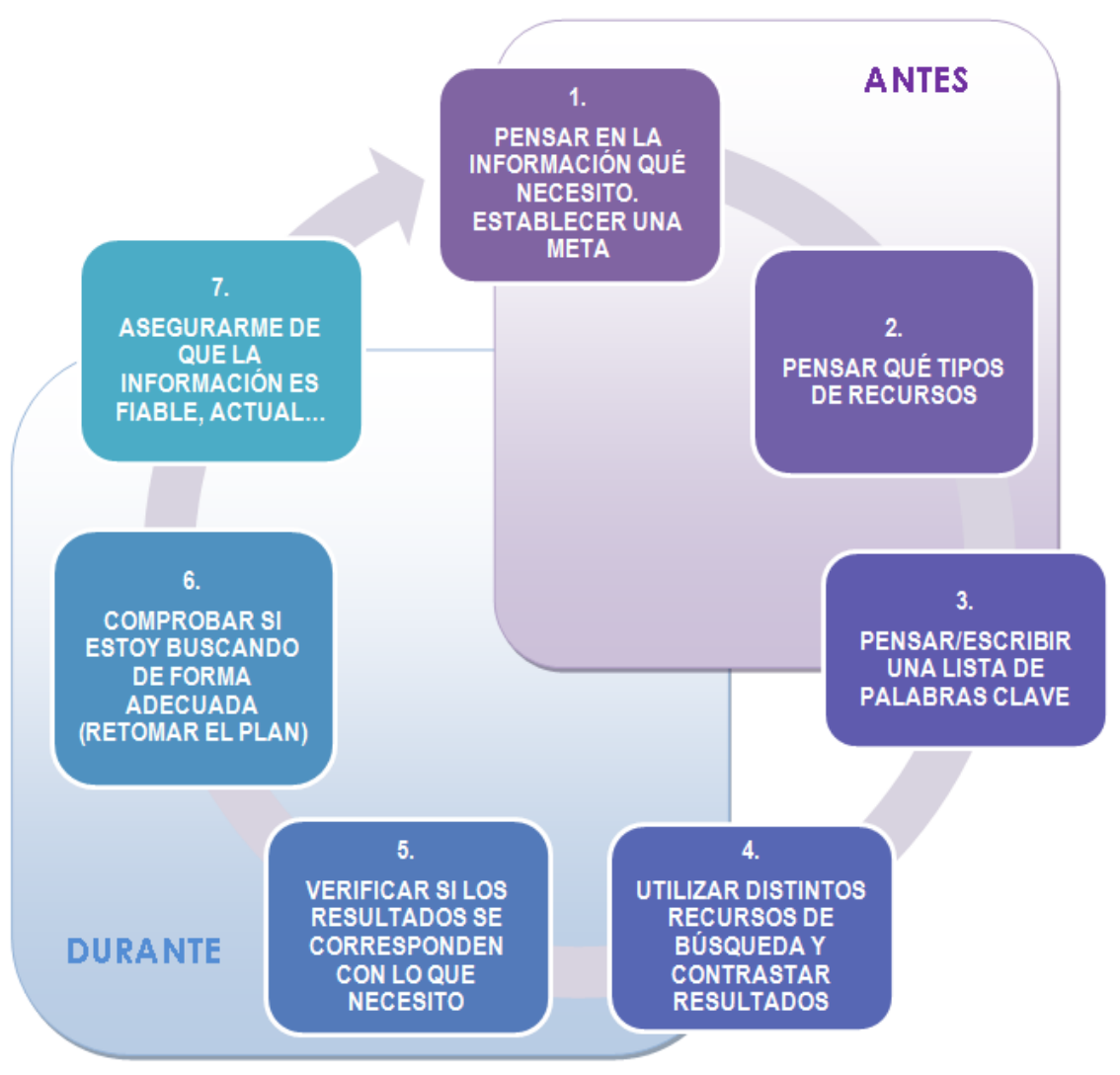

Figura 1: Modelo de las siete acciones estratégicas (antes y durante la búsqueda).

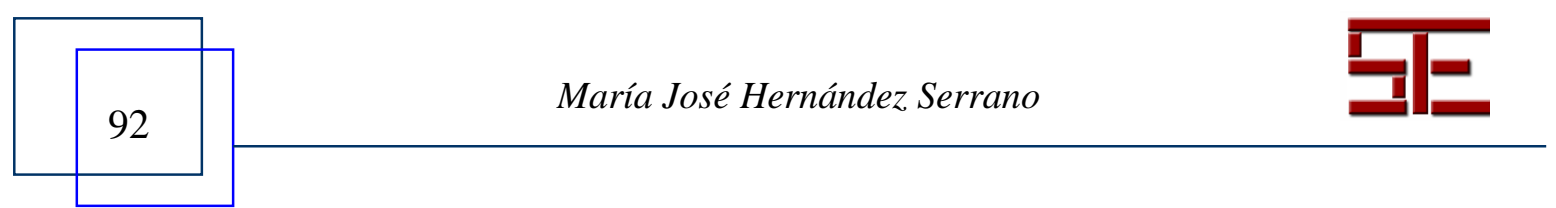




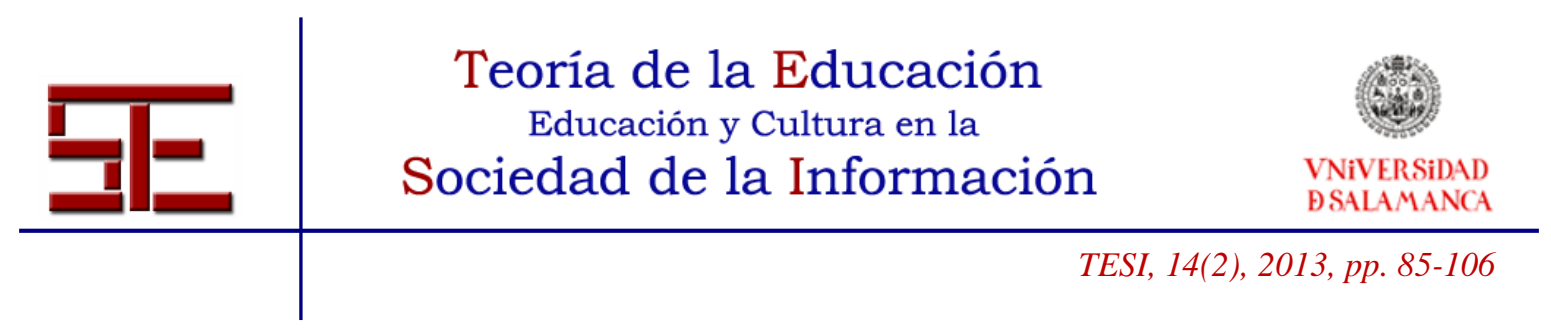

Hay que destacar que el cuestionario comenzaba con una primera pregunta abierta (¿Tienes alguna estrategia que te dé buenos resultados para encontrar información online?) para analizar su concepción general sobre las estrategias asociadas a la actividad de búsqueda y selección online. Para esta pregunta se realizó una categorización de respuestas (Newman, 2003), y posteriormente un análisis de la frecuencia de las categorías con las distintas acciones estratégicas señaladas por los estudiantes.

El tratamiento estadístico de los datos aportados por el cuestionario comprendió, además de un análisis univariante, un análisis bivariante para el estudio de relaciones estadísticamente significativas, con pruebas paramétricas y no paramétricas, de acuerdo a tres variables demográficas (edad, sexo y curso/ciclo) y una cuarta variable de control: haber recibido formación (sobre cómo buscar, o cómo buscar de manera estratégica, como parte del programa de alguna asignatura en la Universidad).

\section{3. - RESULTADOS}

\subsection{Concepción general de las estrategias de búsqueda}

Cuando se preguntaba a los estudiantes si tenían alguna estrategia que les diese buenos resultados para buscar, más de la mitad respondía que no. Entre los que afirmaban que sí $(\mathrm{n}=11)$, las estrategias que nombraban se relacionaban con cierta previsión inicial del proceso: un $7 \%(\mathrm{n}=4)$ reconocía el uso de las comillas y del signo + , y otro $7 \%$ expresaba que lo más importante era delimitar las palabras clave. También un 5\% exponía la importancia de ser crítico. Al analizar la interacción con otras variables se comprobó que todos los sujetos que decían poseer una estrategia habían recibido formación en una asignatura y además eran de segundo ciclo.

Llama la atención que otro $25 \%(\mathrm{n}=15)$ de los estudiantes manifestara que su estrategia era "usar Google", el propio método de acceso a la información, en lugar de acciones de planificación o supervisión.

\subsection{Acciones estratégicas en la primera fase, antes de buscar}

De acuerdo a las valoraciones emitidas por los estudiantes se observó cierta deseabilidad respecto a la categoría eficaz, ya que casi todas las actividades fueron valoradas como eficaces, es decir, que las realizaban y las recomendarían (ver Tabla 1).

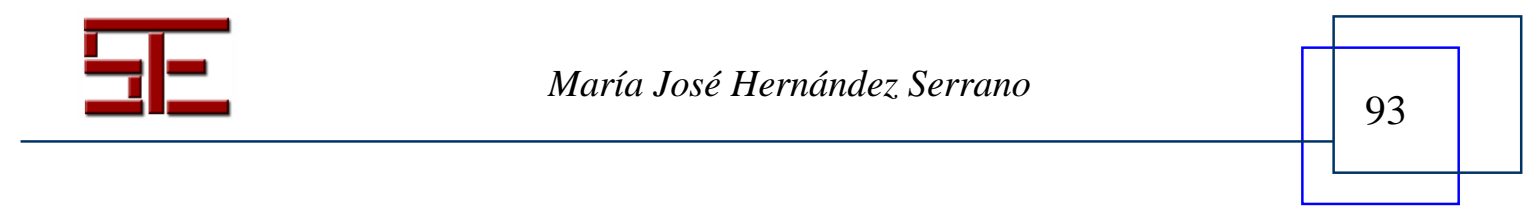




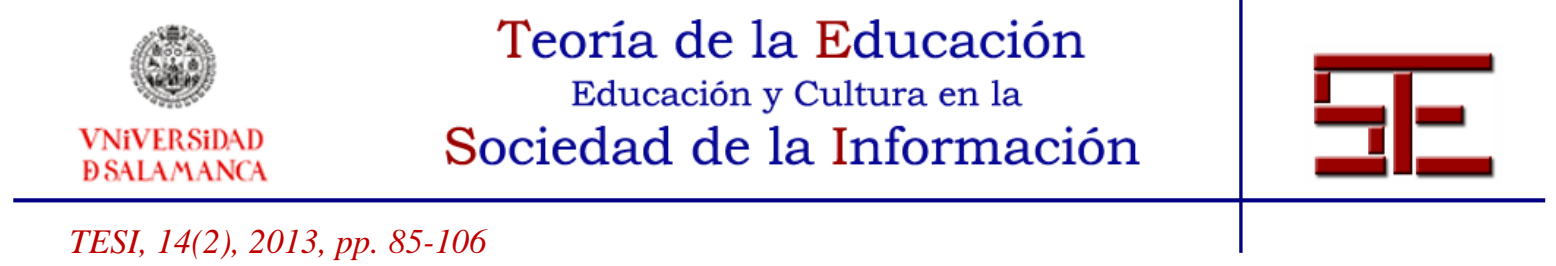

\begin{tabular}{|c|c|c|c|c|}
\hline ACTIVIDADES DE PRE-BUSQUEDA & $\begin{array}{l}\text { EFICAZ } \\
\text { (realizo y } \\
\text { recomiendo) }\end{array}$ & $\begin{array}{l}\text { INEFICAZ } \\
\text { (realizo y no } \\
\text { recomiendo) }\end{array}$ & $\begin{array}{c}\text { UTIL } \\
\text { (no realizo } \\
\text { y } \\
\text { recomiend } \\
\text { o) } \\
\end{array}$ & $\begin{array}{l}\text { INUTIL } \\
\text { (no realizo y } \\
\text { no recomiendo) }\end{array}$ \\
\hline $\begin{array}{l}\text { Comprobar si lo que voy a buscar es algo } \\
\text { general o concreto }\end{array}$ & 43,3 & 15 & 30 & 11,6 \\
\hline $\begin{array}{l}\text { Identificar palabras clave o frases apropiadas } \\
\text { para buscar }\end{array}$ & 75 & 1,6 & 3,3 & 20 \\
\hline $\begin{array}{l}\text { Identificar terminología alternativa: sinónimos, } \\
\text { palabras no relacionadas, palabras en otros } \\
\text { idiomas. }\end{array}$ & 40 & 31,6 & 18,3 & 10 \\
\hline $\begin{array}{l}\text { Utilizar operadores/conectores para construir } \\
\text { búsquedas más precisas (AND, NOT,...) }\end{array}$ & 5 & 48,3 & 45 & 1,6 \\
\hline Utilizar opciones de la búsqueda avanzada & 36,6 & 21,6 & 28,3 & 13,3 \\
\hline $\begin{array}{l}\text { Prever buscar en más de un buscador o en } \\
\text { diferentes recursos de (Google, Yahoo,...) }\end{array}$ & 58,3 & 6,6 & 25 & 10 \\
\hline
\end{tabular}

Tabla 1: Valoración de las actividades estratégicas de la primera fase (\%)

Se evidenció un rechazo elevado hacia el uso de operadores, que muy pocos estudiantes decían que usaban, y la mitad de ellos no tenía predisposición a usar. Lo que más realizaban era el uso de palabras clave $(95 \%$, teniendo en cuenta los que lo recomendarían o no), seguido de la utilización de diferentes recursos de búsqueda $(68,3 \%)$. Lo que más recomendarían (sumando eficacia y utilidad) sería la previsión de la búsqueda en diferentes recursos $(83,3 \%)$, el uso de palabras clave $(78 \%)$ y la determinación del tema como algo general o concreto $(73,3 \%)$, no así el uso funciones avanzadas.

Diferenciando por niveles, se observaron diferencias significativas entre la realización y recomendación de terminología alternativa y el curso $(\mathrm{p}=0,028)$, y entre esta actividad y la formación recibida $(\mathrm{p}=0,014)$. Tales diferencias nos indican que para los sujetos de los niveles superiores, así como para aquellos que habían recibido formación en una asignatura, dicha actividad es eficaz, realizándola y recomendándola; mientras que en los de niveles inferiores, y/o para los que habían aprendido a buscar solos, ni la llevarían a cabo ni la recomendarían.

\subsection{Acciones estratégicas en la segunda fase, durante la búsqueda}

En cuanto a las preferencias de los estudiantes para iniciar la búsqueda, el método predominante fue el uso de los motores de búsqueda (ver Tabla 2), para todos los niveles.

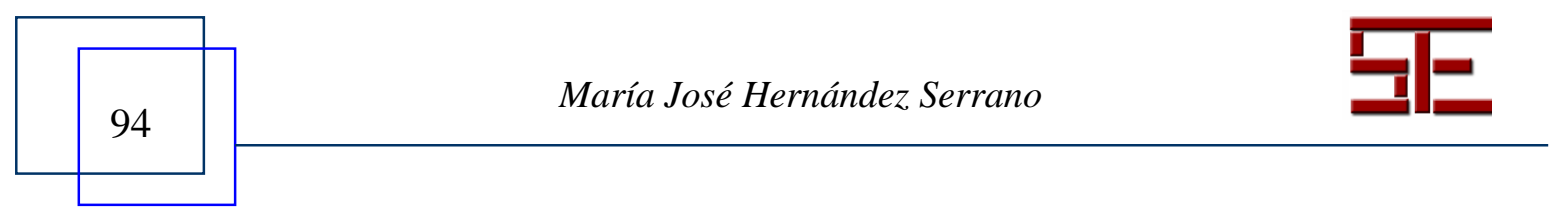




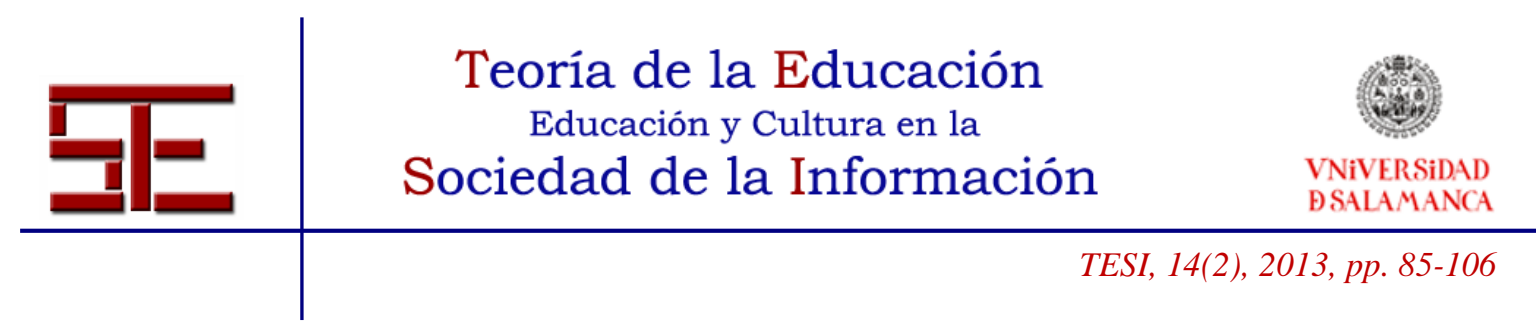

\begin{tabular}{|c|c|c|c|c|c|}
\hline INICIO DE LA BUSQUEDA & $\begin{array}{l}1 \\
\text { NUNCA }\end{array}$ & $\begin{array}{c}2 \\
\text { A VECES }\end{array}$ & $\begin{array}{c}3 \\
\text { SIEMPR } \\
\text { E }\end{array}$ & MEDIA & SD \\
\hline $\begin{array}{l}\text { Visito páginas que conozco para ver si tienen } \\
\text { información sobre lo que quiero }\end{array}$ & 15 & 65 & 16,7 & 2,02 & 0,57 \\
\hline $\begin{array}{l}\text { Visito páginas generales que intuyo pueden tener la } \\
\text { información que busco }\end{array}$ & 23,3 & 56,7 & 16,7 & 1,93 & 0,64 \\
\hline $\begin{array}{l}\text { Pregunto a alguien para que me recomiende dónde } \\
\text { podría encontrarlo }\end{array}$ & 15 & 78,3 & 5 & 1,90 & 0,44 \\
\hline $\begin{array}{l}\text { Utilizo un motor de búsqueda y escribo palabras } \\
\text { clave (ej.: Google) }\end{array}$ & 1,7 & 3,3 & 95 & 2,93 & 0,31 \\
\hline $\begin{array}{l}\text { Utilizo un directorio por categorías y voy } \\
\text { profundizando hasta encontrar el tema que necesito }\end{array}$ & 50 & 36 & 10 & 1,59 & 0,67 \\
\hline
\end{tabular}

Tabla 2: Predisposición del uso de diferentes métodos de inicio de búsqueda (\%)

Un dato importante es el hecho de que, aunque mayoritariamente utilizasen siempre un mismo método de búsqueda (motor), gran parte de ellos también decía utilizar a veces otros métodos de forma simultánea: páginas conocidas y páginas generales $(\mathrm{r}=0,33)$, motor y directorio $(\mathrm{r}=0,27)$.

Se halló una correlación significativamente moderada $(r=0,529)$ entre el hecho de haber recibido formación y la preferencia por el uso de índices, bien como método de búsqueda aislado o complementario. Y también, aunque negativa, una correlación entre la formación recibida y el hecho de preguntar a alguien $(r=-0,279)$.

En esta misma fase, además de analizar el método, también se estudiaron las diferentes decisiones tomadas para seguir buscando (ver Tabla 3). Se observó que las acciones más frecuentes se relacionaban con el uso de más términos o su modificación por otros nuevos. No es frecuente utilizar las opciones avanzadas para ampliar o restringir los resultados.

Se hallaron diferencias significativas en cuanto a la edad y al hecho de retomar la búsqueda $(\mathrm{p}=0,020)$, observándose que los sujetos más mayores eran los que retomaban muchas veces. También encontraron correlaciones entre el hecho de haber recibido formación en una asignatura y el uso de opciones avanzadas ( $\mathrm{r}=0,342)$; es decir, que sólo utilizaban las opciones avanzadas quienes las conocían.

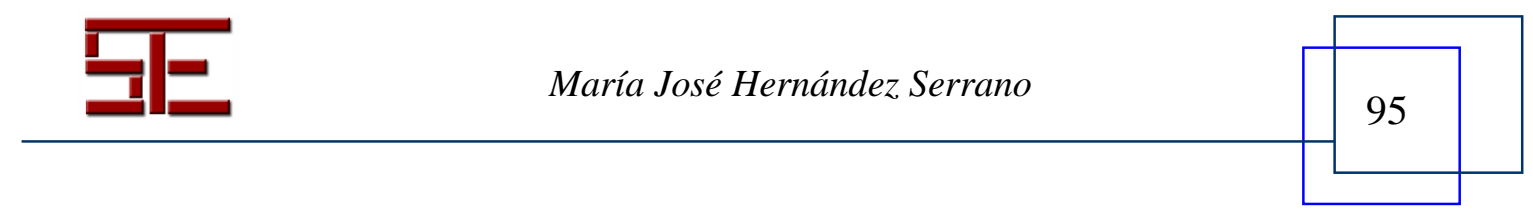




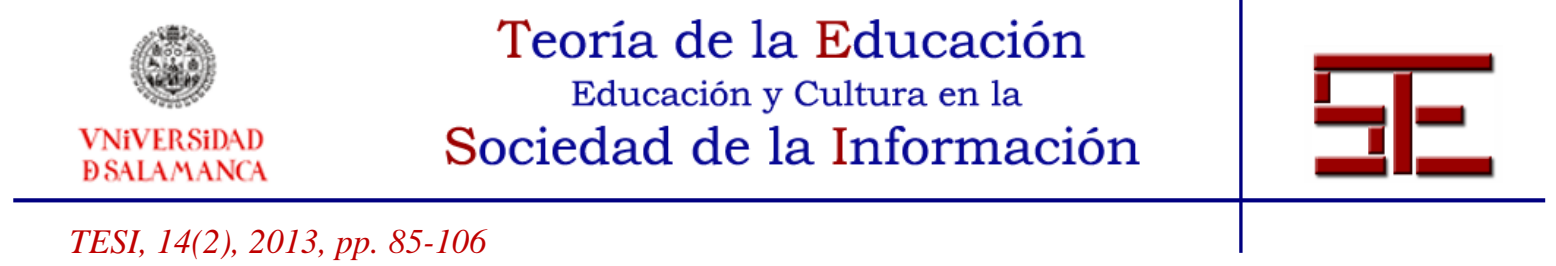

\begin{tabular}{|c|c|c|c|c|c|c|c|c|}
\hline $\begin{array}{l}\text { CONTINUACIÓN } \\
\text { DELAA BUSSQUEDA }\end{array}$ & $\begin{array}{c}0 \\
\text { Nunca }\end{array}$ & $\begin{array}{l}1 \\
\text { Muy } \\
\text { pocas } \\
\text { veces }\end{array}$ & $\begin{array}{c}2 \\
\text { Algunas } \\
\text { veces }\end{array}$ & $\begin{array}{l}3 \\
\text { Muchas } \\
\text { veces }\end{array}$ & $\begin{array}{l}4 \\
\text { Mayoría } \\
\text { de las } \\
\text { veces }\end{array}$ & $\begin{array}{c}5 \\
\\
\end{array}$ & Media & $S D$ \\
\hline $\begin{array}{l}\text { Añadir nuevos términos de } \\
\text { búsqueda relacionados con lo } \\
\text { ya revisado }\end{array}$ & - & 3,3 & 31,7 & 38,3 & 20 & 6,7 & 2,95 & 0,96 \\
\hline $\begin{array}{l}\text { Utilizar opciones de búsqueda } \\
\text { avanzada para ampliar o } \\
\text { reducir los resultados }\end{array}$ & 15 & 18,3 & 33,3 & 25 & 6,7 & 1,7 & 1,95 & 1,21 \\
\hline $\begin{array}{l}\text { Retomar en el lugar que se } \\
\text { había abandonado }\end{array}$ & 3,3 & 15 & 56,7 & 18,3 & 6,7 & - & 2,10 & 0,85 \\
\hline $\begin{array}{llll}\begin{array}{l}\text { Cambiar } \\
\text { búsqueda }\end{array} & \text { recurso } & \text { de } \\
\end{array}$ & 11,7 & 25 & 48 & 10 & 5 & - & 1,72 & 0,97 \\
\hline
\end{tabular}

Tabla 3: Porcentaje de frecuencias de actividades durante la búsqueda (\%).

Finalmente, para terminar la búsqueda hay una serie de razones que llevan a decidir si se termina o se desestima, porque no se está cumpliendo con los objetivos que se persiguen. Para los estudiantes analizados la principal razón para terminar, indiscutiblemente, es percibir que no se encuentra lo que exactamente se necesita $(79 \%, \mathrm{n}=47)$; a continuación se situaron la no percepción de unos mínimos de calidad en la información (no era actual, no era demasiado fiable o era comercial) $(35 \%, \mathrm{n}=21)$, el hecho de que se terminó de buscar todo lo que ofrecía el buscador $(31,6 \%, \mathrm{n}=19)$ o se estaba tardando demasiado $(30 \%, \mathrm{n}=18)$, $\mathrm{y}$, en menor porcentaje, de que se aburrían al no haber nada interesante $(25 \%, \mathrm{n}=15)$ o no encontraban información en su idioma, sobre su país, etc. $(11 \%, \mathrm{n}=6)$.

\subsection{Valoración del modelo de siete acciones estratégicas}

Los estudiantes valoraron la importancia de las siete actividades del modelo de manera altamente positiva, por encima de la importancia mediana (ver Tabla 4). Las tres primeras se corresponderían con la primera fase, antes de buscar, y las cuatro restantes con la segunda fase, durante la búsqueda y selección de la información online.

La mayor parte de los estudiantes coincidió en que lo que más le ayudaría sería asegurarse de que la información es fiable $(\mathrm{SD}=0,839 ; \mathrm{Mo}=5)$; por el contrario, lo que menos les ayudaría sería pensar en una lista de palabras clave e irlas combinando ( $\mathrm{SD}=1,288$; $\mathrm{Mo}=3$ ). Respecto a las acciones referidas a la primera fase (antes), lo que consideraban que en mayor medida les podría ayudar a tener éxito sería pensar inicialmente las posibilidades de los diferentes recursos y herramientas de búsqueda, para utilizar los que

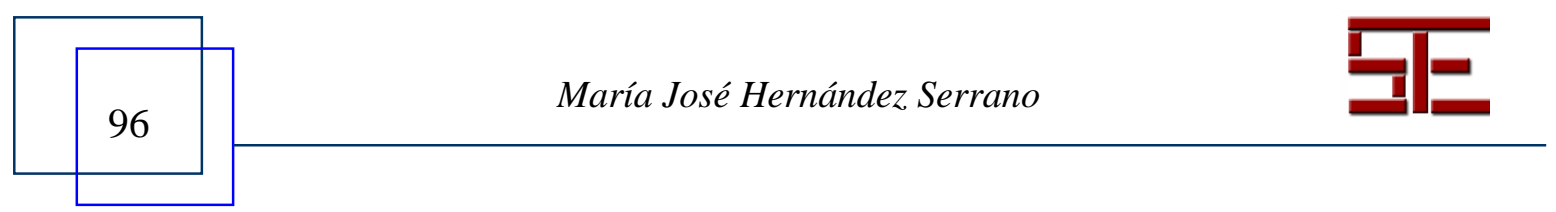




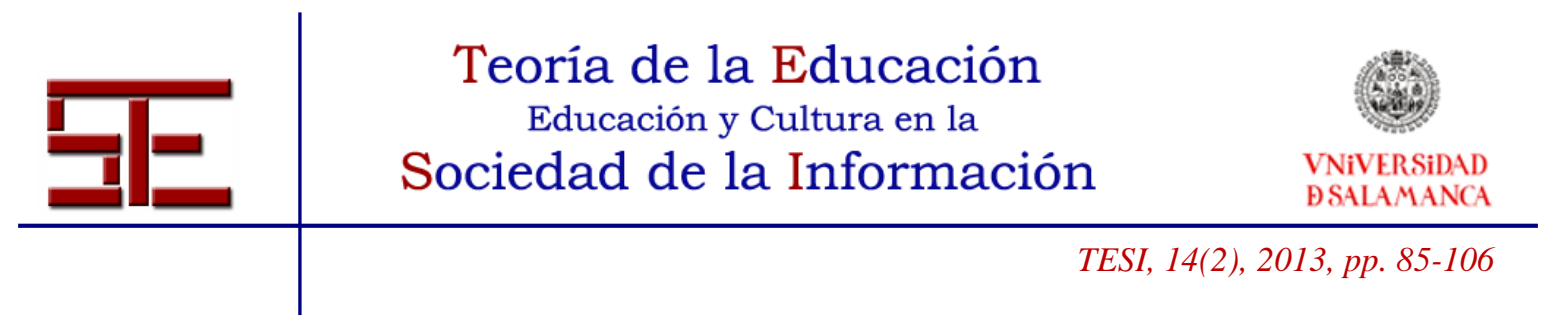

pudieran ser más acertados $(45 \%, \mathrm{n}=27)$. Respecto a las acciones de la segunda fase (durante), la mayor parte de los sujetos entendía que utilizar diferentes recursos y contrastarlos sería bastante o muy importante y el $70 \%$ opinaba que sería bastante o muy importante realizar un seguimiento de los resultados y del proceso.

\begin{tabular}{|c|c|c|c|c|c|c|c|}
\hline ACTIVIDADES ESTRATEGICAS & $\begin{array}{c}1 \\
\mathrm{Nada}\end{array}$ & $\begin{array}{c}2 \\
\text { Poco }\end{array}$ & $\begin{array}{c}3 \\
\text { Normal }\end{array}$ & $\begin{array}{c}4 \\
\text { Bastan } \\
\text { te }\end{array}$ & $\begin{array}{c}5 \\
\text { Muc } \\
\text { ho }\end{array}$ & $\begin{array}{c}\text { Med } \\
\text { ia }\end{array}$ & SD \\
\hline $1 \begin{array}{l}\text { Pensar en la información que necesito y establecer } \\
\text { una meta para tener claro lo que quiero buscar }\end{array}$ & - & 22,4 & 24,1 & 37,9 & 15,5 & 3,47 & 1,01 \\
\hline $\begin{array}{l}2 \text { Pensar qué tipo de recurso puede ser más acertado } \\
\text { para ayudarme a resolver lo que necesito }\end{array}$ & 1,7 & 6,9 & 37,6 & 44,8 & 19 & 3,72 & 0,91 \\
\hline $\begin{array}{l}3 \text { Pensar o escribir una lista de palabras relacionadas } \\
\text { con lo que quiero buscar y combinarlas }\end{array}$ & 15 & 8,6 & 29,3 & 29,3 & 17,2 & 3,24 & 1,28 \\
\hline $4 \begin{array}{l}\text { Utilizar distintos recursos de búsqueda de forma } \\
\text { simultánea y contrastar los resultados que ofrecen }\end{array}$ & 1,7 & 6,9 & 29,3 & 46,6 & 15,5 & 3,67 & 0,88 \\
\hline $\begin{array}{ll}5 \text { Verificar si los resultados que encuentro se } \\
\text { corresponden con lo que necesito }\end{array}$ & 1,7 & 3,4 & 15,5 & 39,7 & 39,7 & 4,12 & 0,91 \\
\hline $\begin{array}{l}6 \text { Comprobar si estoy buscando de forma adecuada, y } \\
\text { si no es así pensar qué puedo hacer para cambiar }\end{array}$ & 1,7 & 5,2 & 24,1 & 39,7 & 29,3 & 3,90 & 0,94 \\
\hline $\begin{array}{l}7 \text { Asegurarme de que la información encontrada es } \\
\text { fiable, actual, segura... }\end{array}$ & - & 3,4 & 15,5 & 36,2 & 44,8 & 4,22 & 0,83 \\
\hline
\end{tabular}

Tabla 4: Valoración de importancia de las acciones estratégicas del modelo (\%)

Aunque no se hallaron diferencias estadísticamente significativas por cursos/nivel, se observó que las actividades de la segunda fase fueron valoradas en orden creciente, encontrándose que los estudiantes de los cursos superiores concedieron mayor grado de importancia a las cuatro acciones de esta fase. Sin embargo, la tendencia para las acciones estratégicas de la primera fase parecía ser similar en los diferentes cursos.

Al realizar un análisis de componentes principales con las siete acciones del modelo propuesto se observó cómo las actividades se agrupaban en dos factores (K.M.O.=0,706; Esfericidad $\mathrm{p}=0,002$; rotación Varimax, $60 \%$ de la variabilidad explicada). Por una parte, lo que podríamos denominar actividades básicas o primarias, que comprenderían: 1, 2, 5, 6 y 7. Y, por otra, según la agrupación mostrada por el otro factor, lo que serían actividades complementarias, de segundo orden, o no tan prioritarias como las anteriores, que incluirían las acciones 3 y 4.

Si analizamos la valoración de los sujetos para estos dos nuevos factores, se observa, como se muestra en las siguientes gráficas (Figura 2), que los cursos de primer ciclo fueron más variables en sus respuestas, ya que el rango fue mayor que en los últimos

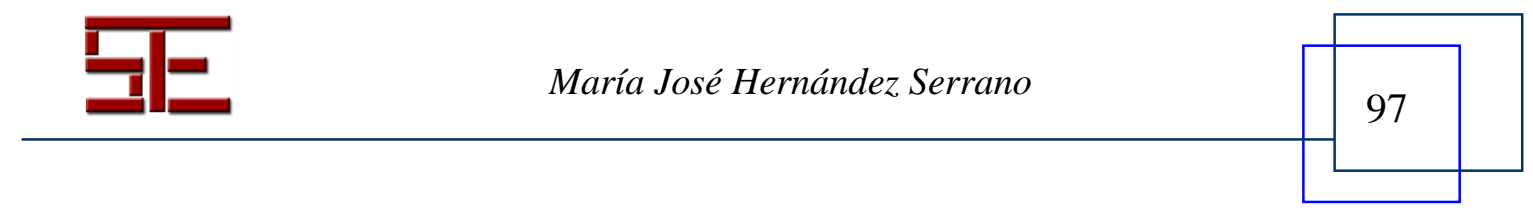




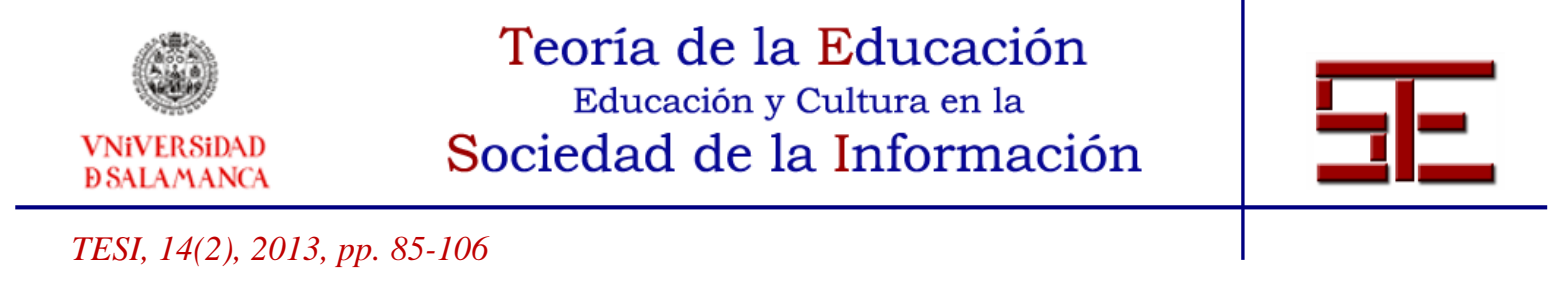

cursos. Los estudiantes de primer curso valoraron negativamente las actividades complementarias y muy poco las básicas, la mayor parte de ellos por debajo de la media, al contrario que los de segundo curso; el curso de tercero fue el que más predisposición estratégica positiva reveló, ya que juzgó con mucho grado de importancia los dos tipos de actividades; finalmente, los alumnos de cuarto curso, para quienes no se observó tanta dispersión y sobrevaloraron las complementarias por encima de las básicas.

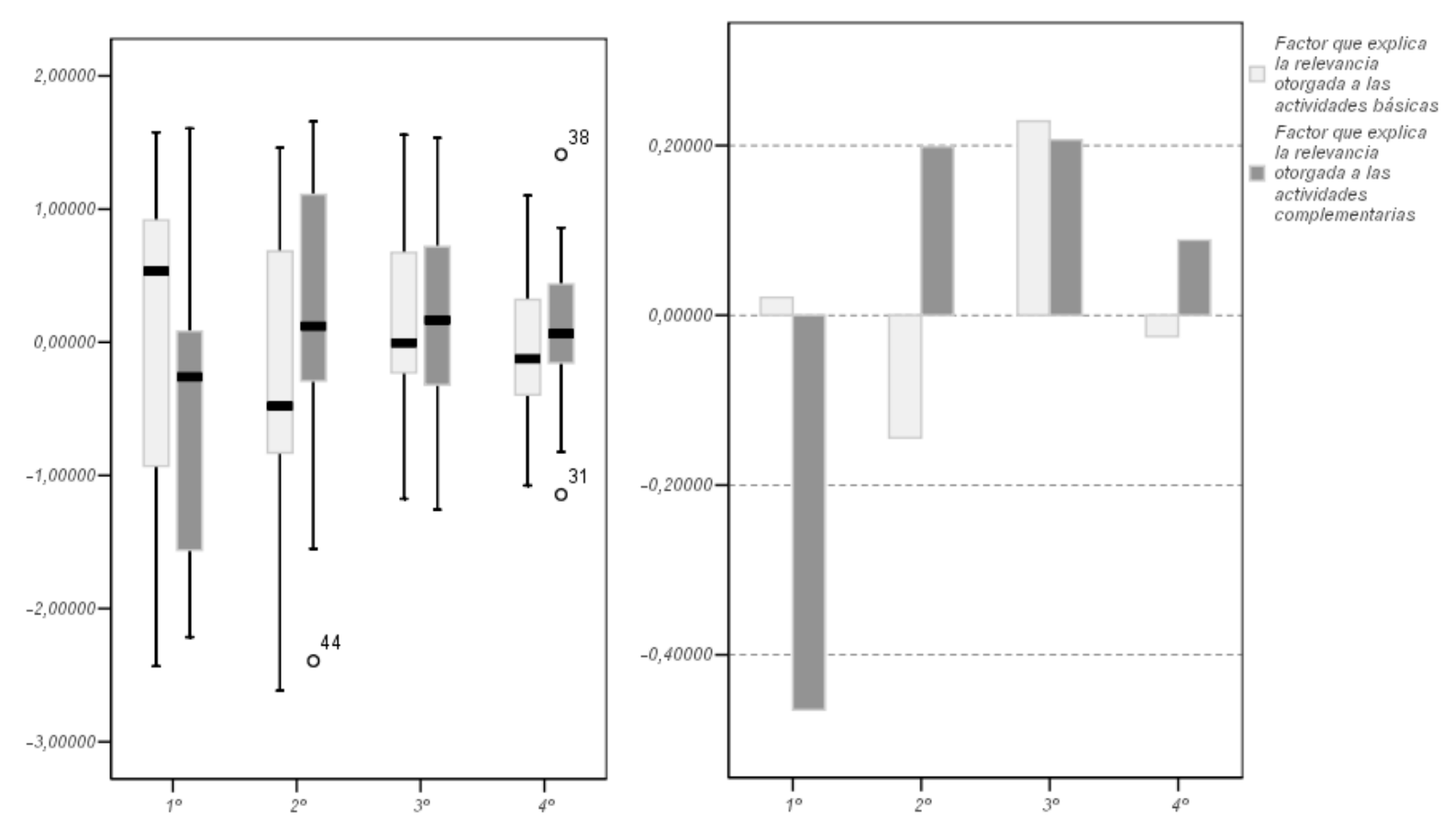

Figura 2: Diagrama de cajas y barras para la valoración de los factores extraídos de las actividades por cursos según media.

\section{4. - DISCUSIÓN}

El hallazgo más significativo en cuanto al comportamiento estratégico es que los estudiantes tienen una concepción muy vaga de lo que significa ser estratégico en la búsqueda de información en Internet. Confunden la posesión de una estrategia con la preferencia de uso de un recurso ( el 25\% manifestó que su estrategia era usar Google).

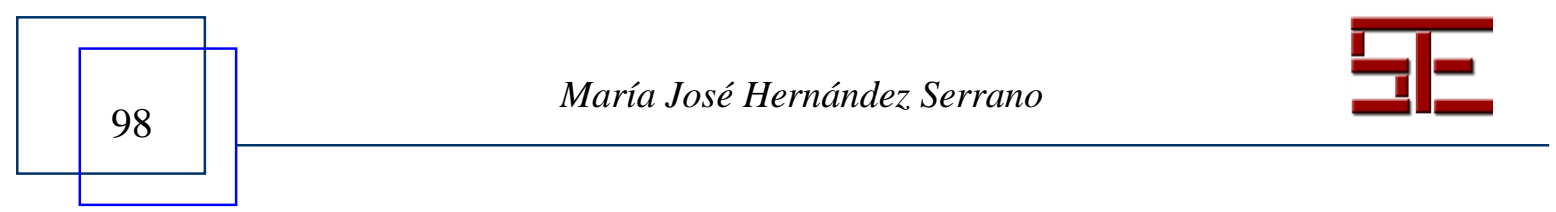




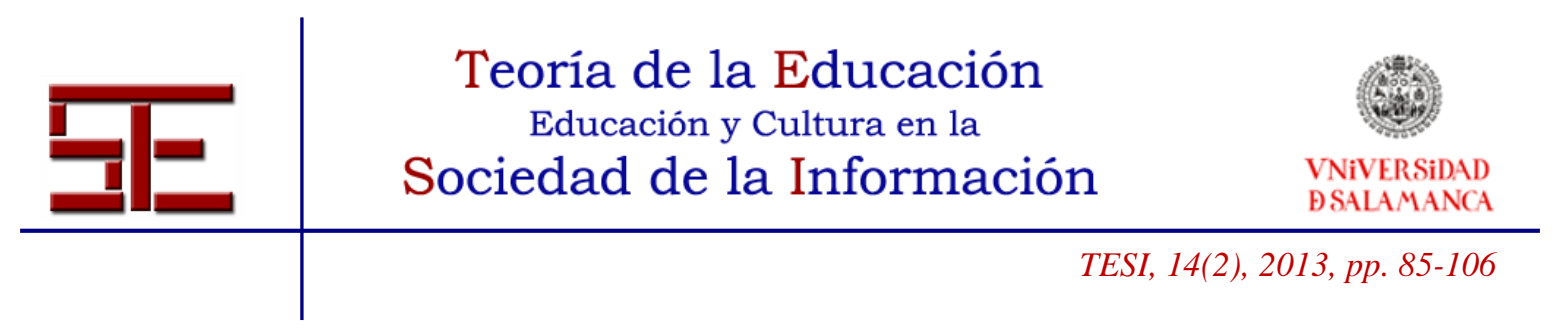

Esto pone de relieve que los estudiantes confían excesivamente en algunos recursos, que supuestamente les reportan éxito para encontrar lo que necesitan, sin que ellos tengan que realizar ninguna actividad de planificación o control. Lo más llamativo es que esta predisposición proviene principalmente de los estudiantes de primer ciclo, que además no han recibido formación.

Los estudiantes que enfocan la búsqueda desde planteamientos estratégicos son sólo una minoría, si bien parece que su predisposición para realizar en un futuro estas acciones sí es positiva, ya que la mayoría consideran eficaces casi todas las actividades de planificación y supervisión. De sus valoraciones se desprende que, como principal método de planificación, y dado que el uso preferente de búsqueda es el uso siempre de un motor (95\%), lo que más consideran que funcionaría sería la previsión de palabras clave (78\%); lo que mayoritariamente recomendarían $(83,3 \%)$ sería prever varios recursos de búsqueda, siendo casi la mitad de ellos los que afirmaban que esta actividad les ayudaría bastante a obtener éxito. Sin embargo, en el modelo, dicha actividad es valorada como complementaria, siendo sólo estimada por los estudiantes de primer ciclo.

También consideraron complementario el pensar una lista de palabras, o identificar otro tipo de terminología relacionada (el 31,6\% lo consideró ineficaz), y sólo un 17,2\% considera que dicha actividad le ayudaría mucho a obtener éxito. Respecto a otros aspectos, pensar en el tema y clasificarlo como general o concreto es algo que la mitad de ellos no hace, pero que mayoritariamente sí piensa que puede funcionar $(73,3 \%)$. Sin embargo, si se trata de valorar el tema para establecer una meta, el 46,5\% no lo considera muy importante, especialmente algunos alumnos del último curso; este resultado es llamativo, ya que, precisamente, el establecimiento de una meta puede ayudarles a no desorientarse y a no perderse.

Quizás, a la falta de predisposición estratégica para planificar hay que añadir el desconocimiento de los efectos de las acciones estratégicas. Un estudiante no se planteará realizar una búsqueda estratégica si no concibe que dichas estrategias le llevarán a obtener más éxito en términos de calidad de los resultados o del proceso; nunca midiendo el éxito en base a criterios temporales, ya que la reflexión y, supervisión del proceso demorarán el tiempo a emplear para buscar y seleccionar. Aquí es donde hallamos un vacío formativo, y donde la pedagogía puede apostar por nuevas áreas de estudio que ayuden a enfocar acciones cotidianas como la búsqueda de información, hacia planteamientos estratégicos que lleven a procesos más eficaces y significativos.

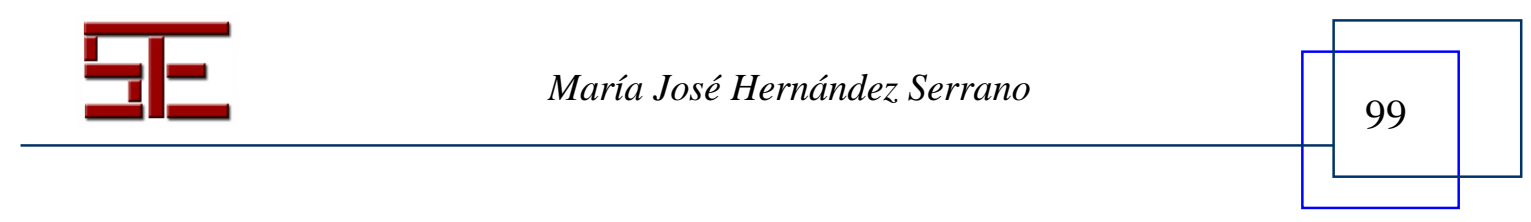




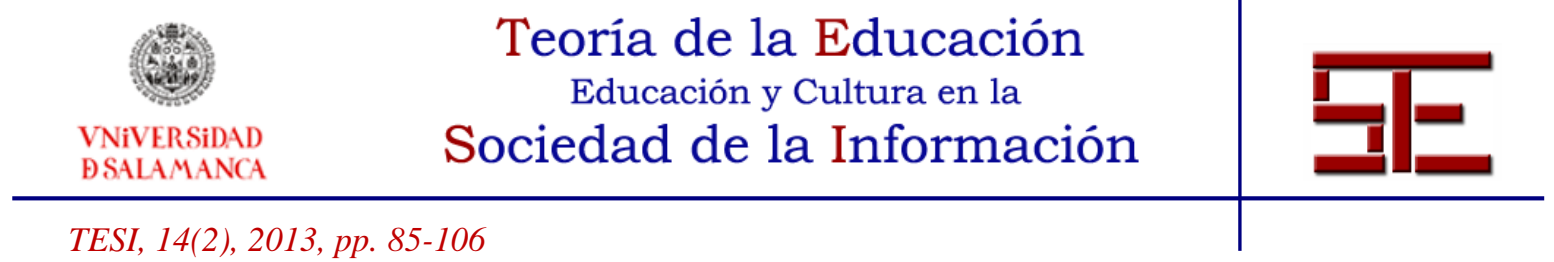

Los resultados han mostrado que al menos a nivel inicial, es decir, para la primera fase de planificación previa del proceso, los sujetos no mantienen una predisposición muy positiva, no considerando muy necesario realizar acciones estratégicas. Cierto es que mayoritariamente su forma de buscar se ajusta a un esquema único, basado en el uso de un motor y la escritura de un número escaso de palabras clave. Si este método, además de rápido, les resulta eficaz (Jansen, 2000; Jansen y Spink, 2006), pocos se plantearán modificar este patrón y resultará difícil alterar la orientación de sus prácticas para cambiarlas por otras más reflexivas. En general, la poca valoración hacia la planificación también ha sido confirmada por otros estudios en los que también se concluye que los estudiantes apenas planifican previamente sus búsquedas (Monereo et al., 2000; Bilal y Kirby, 2001; Savolainen y Kari, 2006) ni se plantean que sea necesario hacerlo (Guinee, 2004).

Tampoco existe una predisposición elevada respecto a las acciones estratégicas propias de la segunda fase. Durante la búsqueda apenas se plantean modificar los términos empleados, sus procesos se caracterizan más bien por sesiones de búsqueda única. Sólo un $6,7 \%$ afirmó que añadía términos siempre, utilizando la información que iba localizando para reformular y ajustar sus búsquedas. Principalmente, se evidencia cierto conformismo con los resultados que ofrece el buscador. Sin embargo, el hecho de que más de la mitad de los sujetos retome algunas veces la búsqueda inicial demuestra que, realmente se trata de un proceso iterativo en el que se avanza adelante y atrás, en el cual, además, los sujetos más mayores $(\mathrm{p}=0,020)$ son los que con más frecuencia vuelven a situarse en búsquedas iniciales. Frente a una búsqueda irreflexiva, la atención consciente hacia el proceso favorece, en mayor o menor grado, el control sobre el tipo de información a encontrar, para evitar sentirse desorientado, o perdido, teniendo que iniciar de nuevo la búsqueda. Para finalizar, respecto a las señales que les ayudan a determinar cuándo se debe terminar el proceso de búsqueda, lo principal es el ajuste a la necesidad informativa (79\%). En un porcentaje similar consideran que verificar la coherencia entre la necesidad informativa y los resultados les ayudaría mucho a obtener éxito, aunque los estudiantes de los primeros cursos no estuvieran muy de acuerdo en ello. Llama la atención que sólo un tercio no concluiría el proceso si no detecta calidad, veracidad y fiabilidad y que los que más valoraron estos criterios fueron los sujetos de segundo ciclo, especialmente los del último curso. Hay otras dificultades que les llevarían a abandonar la búsqueda, también observadas en otros estudios, relacionadas con el hecho de tardar demasiado tiempo (Griffiths y Brophy, 2002), así como inconvenientes idiomáticos (Monereo et al., 2000). De nuevo encontramos que para los estudiantes el tiempo a emplear es un factor que utilizan para valorar la eficacia del proceso.

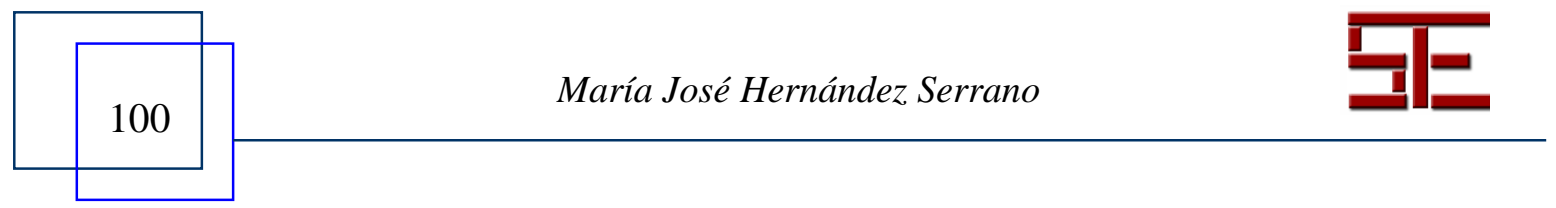




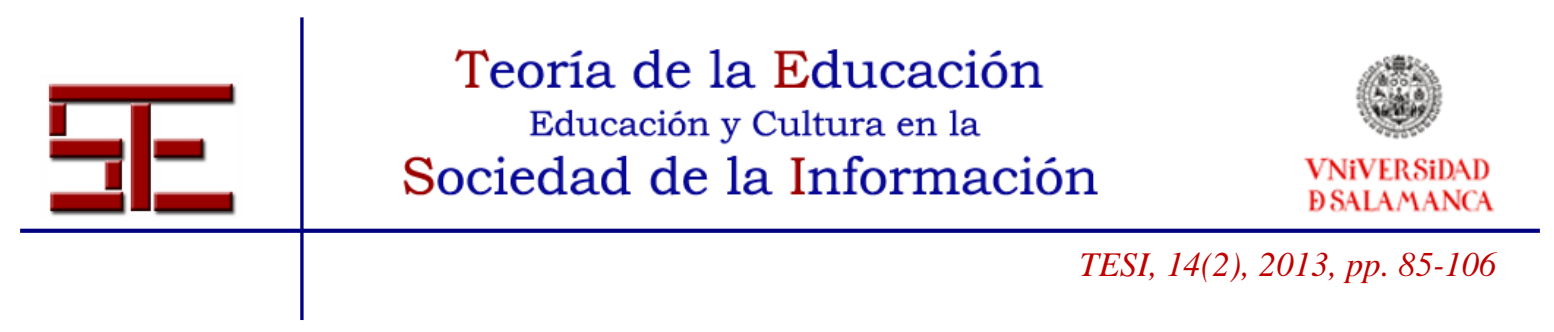

Parece que terminar de buscar es una decisión poco guiada por planteamientos reflexivos, en la que al menos preguntarse si la información encontrada concuerda con lo que se necesita es algo que sí realizan y consideran necesario realizar. No en vano, vemos cómo el ajuste temático resultó más importante para ellos que la evaluación crítica.

Los dos factores que se obtuvieron en este estudio, aunque orientativos, dan cuenta de la relevancia que los primeros y los últimos cursos otorgan a las actividades estratégicas de planificación, reflexión y control sobre la tarea de búsqueda; de cómo los cursos de primer ciclo son mayormente intuitivos e irreflexivos, apenas valorando, o valorando negativamente, las actividades más básicas; y de cómo, por el contrario, los últimos cursos, que ya han podido descubrir la importancia de las actividades básicas, empiezan a preocuparse por las complementarias. En este sentido, parece conveniente seguir trabajando sobre estos aspectos fundamentalmente con los alumnos de los primeros cursos, para los que parece que la búsqueda es una actividad sencilla y rápida, donde se confía en lo que el buscador ofrece y la menor experiencia resolviendo tareas de búsqueda puede estar mediando en su menor predisposición estratégica.

Todo lo expuesto nos lleva a pensar que los estudiantes apenas emplean acciones estratégicas en la búsqueda y selección de información online, ni antes ni durante el propio proceso. La tarea de búsqueda y selección de información, por tanto, y en principio, por sus valoraciones, no es identificada por los estudiantes universitarios como una tarea compleja, que precise planificación, orientación a metas o supervisión. No obstante, no debemos considerar a partir de estas valoraciones que los estudiantes no puedan o no vayan a recurrir a un desempeño estratégico, atento y planificador cuando buscan. En muchas ocasiones estas acciones se producen a un nivel que puede no ser consciente para los estudiantes, es decir, que pueden estar siendo estratégicos sin ser conscientes de ello. Por ello, y a partir de este trabajo, sería conveniente seguir investigando no sólo ya la predisposición, sino los contextos y las situaciones donde el buscar y seleccionar información requiere un afrontamiento estratégico para cada sujeto. Y a partir de ahí derivar directrices pedagógicas que reviertan en la formación de los sujetos reflexivos y estratégicos, capacitados para aprender en actividades mediadas por las TIC.

\section{5. - CONCLUSIONES}

En este artículo nos hemos preguntado por la relevancia de las acciones estratégicas aplicadas a la actividad de búsqueda y selección de información online. A nivel teórico,

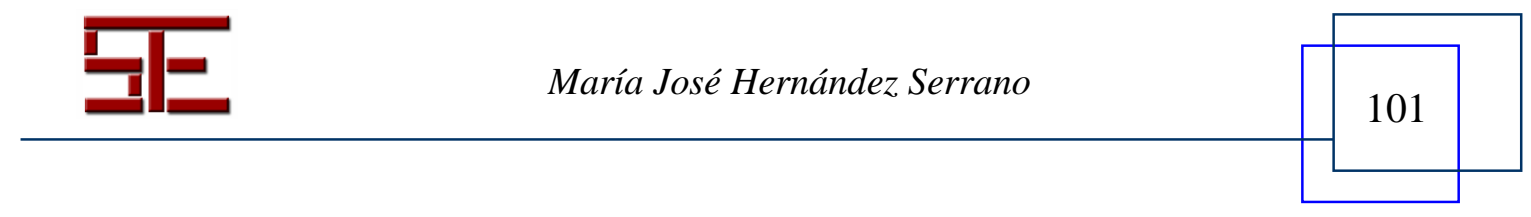




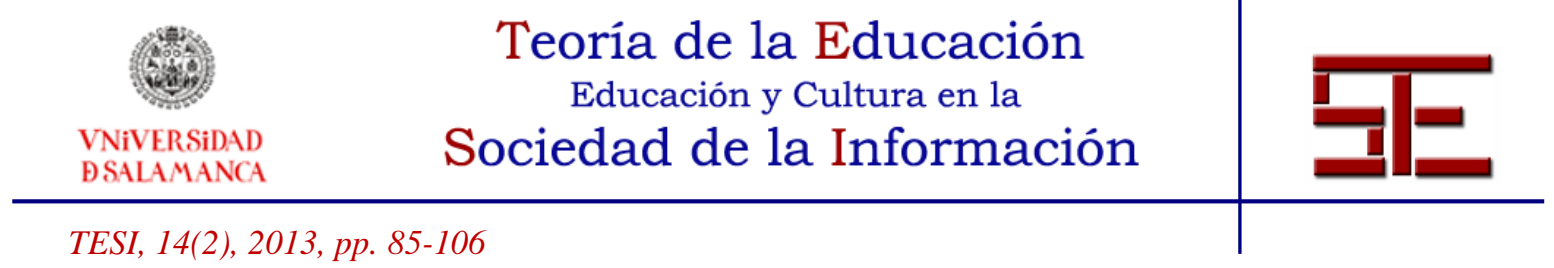

hemos descrito esta actividad como una tarea compleja, y al mismo tiempo muy completa, ya que permite ejecutar procesos cognitivos de alto nivel como son planificar, contrastar, seleccionar, analizar, sintetizar, comparar o evaluar críticamente la información. Estas acciones se ponen en marcha ante tareas que no son rutinarias, y que precisan de procedimientos estratégicos. Se verifica la importancia que adquieren las acciones estratégicas para la eficacia de la actividad de búsqueda, aún más para búsquedas desarrolladas en entornos académicos.

Sin embargo, a nivel práctico, y de acuerdo a los datos presentados en el estudio, al analizar la predisposición estratégica de los estudiantes universitarios frente a la actividad de búsqueda y selección de la información online, observamos que éstos no se plantean dicha actividad como una tarea compleja, sino sencilla, rápida y rutinaria. Sólo los alumnos de los cursos superiores consideran importante la planificación y supervisión. De manera favorable, la valoración sobre la importancia que les merecen estas acciones, en general, es positiva, aunque para algunas acciones (buscar en diferentes recursos, pensar una meta, asegurar fiabilidad) más que para otras (pensar palabras clave, utilizar operadores). Parece que existe una buena predisposición hacia el aprendizaje de algunas acciones estratégicas, que pueden y deben trabajarse en la formación de los estudiantes universitarios.

No obstante, consideramos que una variable que convendría seguir estudiando es el impacto de la formación recibida. Mientras que este estudio se realizó con alumnos de licenciatura, y la formación recibida sobre cómo buscar y seleccionar fue muy limitada, convendría investigar cuál es la predisposición estratégica que demuestran los estudiantes de grado, a quienes en su formación genérica se les incluye una materia sobre tecnologías, y donde se espera se aborde el aprendizaje de estos procedimientos estratégicos aplicados al contex to de la búsqueda de información.

Insistimos en la necesidad de adquirir habilidades relacionadas con la búsqueda, localización, recogida y selección de información, las cuales se revelan fundamentales para ayudar a los alumnos a convertirse en buscadores estratégicos, capaces de seguir un proceso sistemático y regulado (García Carrasco et al., 2012). Se precisa formar a los estudiantes en estrategias de búsqueda y selección de información, y no sólo en el uso de recursos útiles de información, porque son precisamente las estrategias las que se necesitan en contextos complejos y cambiantes.

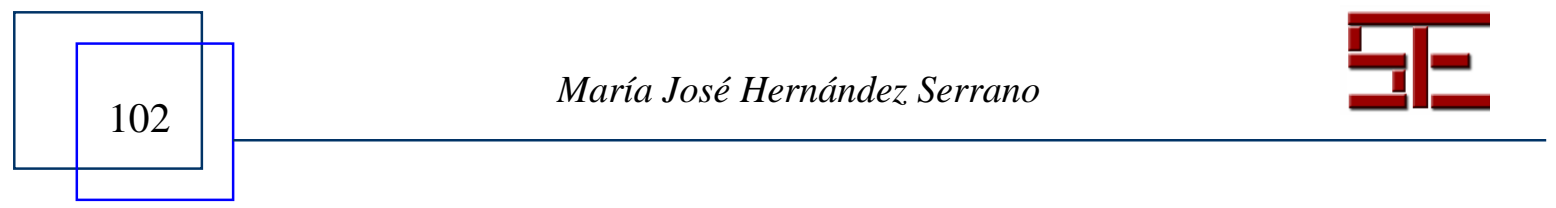




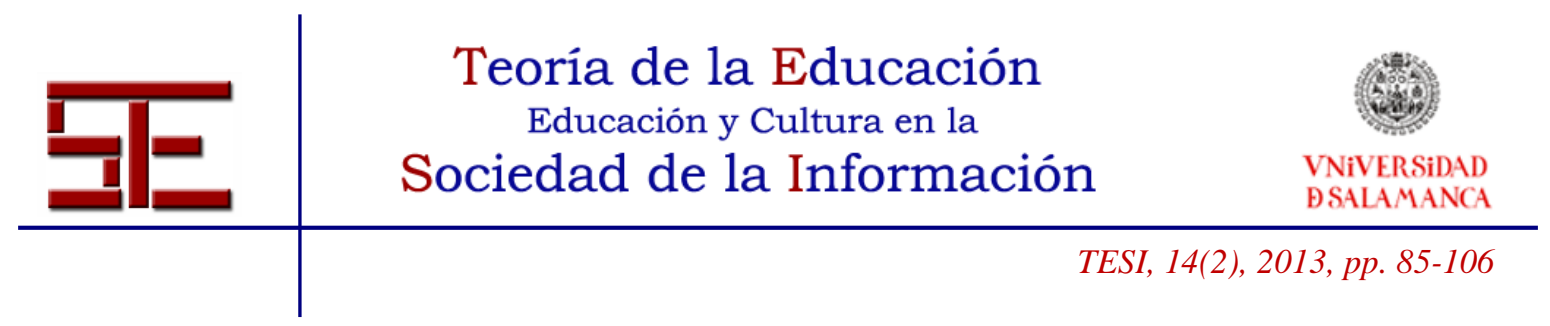

\section{6.- BIBLIOGRAFÍA}

Bilal, D., y Kirby, J. (2001). Factors influencing children's and adults' information seeking on the Web: Results of two studies. Proceedings of the 64th ASIST Annual Meeting, November 4-8, 2001, Washington, DC, 126-140.

Boekaerts, M. (1999). Self-regulated learning: where we are today. International Journal of Educational Research, 31, 445-457.

Chung, J. S. y Newman, D. (2007). High school students' information seeking ans use for class projects. Journal of the America Society for information Science and Technology, 58 (10), 1503-1517.

García Carrasco, J.; Gargallo López, B.; García Manzano, A. y Sánchez I Peris, F. (2012). Nuevos modos de aprendizaje en el contexto de la sociedad del conocimiento. XXXI Seminario Interuniversitario de Teoría de la Educación: Sociedad del Conocimiento y Educación. Plasencia: UNED.

Gargallo, B. (2000). Estrategias de aprendizaje: un programa de intervención para ESO y EPA. Madrid: MECD.

Griffiths, J. R. y Brophy, P. (2002). Student searching behaviour in the JSIC Information environment. Ariadne, 33. Consultado el 2 de junio de 2004, en. http://www.ariadne.ac.uk/issue33/edner

Guinee, K. (2004). Internet searching by K-12 students: a research-based process model. Paper from: Association for Education Communication and Technology, October. Chicago. ERIC: ED485138.

Hernández Serrano, M. J. (2009). Estrategias de búsqueda de información para la generación de conocimiento en la Red. Tesis doctoral. Salamanca, Ediciones Universidad de Salamanca.

Hernández Serrano, M. J. \& Fuentes Agustí, M. (2011). Aprender a informarse en la red: ¿son los estudiantes eficientes buscando y seleccionando información? Revista Teoría de la Educación: Educación y Cultura en la Sociedad de la Información, 47-78.

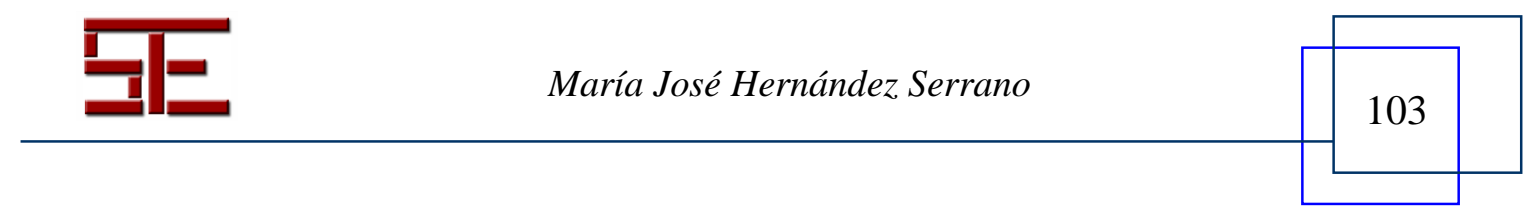




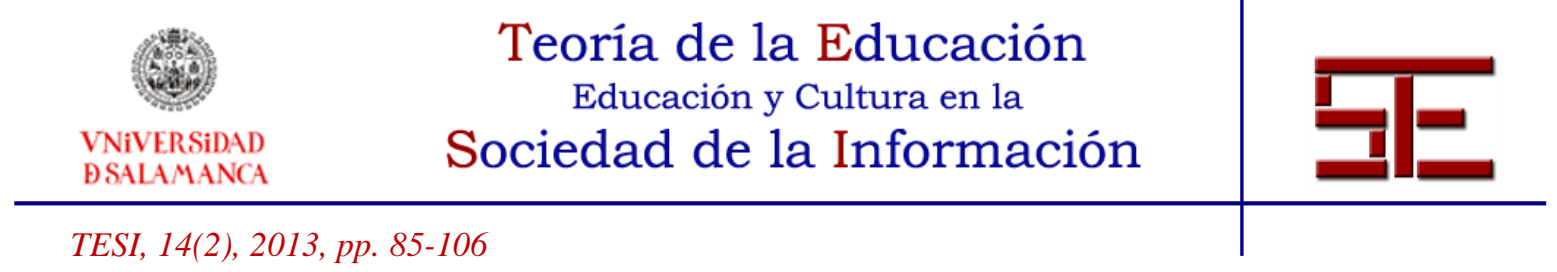

Hernández Serrano, M. J., Jones, B. y González, M. (2011). La generación Google. Evolución en las predisposiciones y comportamientos informativos de los jóvenes. Revista Interuniversitaria de Pedagogía Social, 18, 41-56.

Hughes, H. (2009). International students using online information to learn. Doctoral Thesis. Queensland University of Technology.

Innerarity, D. (2011). La democracia del conocimiento. Por una Sociedad inteligente. Barcelona: Paidós.

Jansen, B. J. (2000). The effect of query complexity on Web searching results. Information Research 6 (1).

Jansen, B. J. y Spink, A. (2006). How are we searching the World Wide Web? A comparision of nine search engine transition logs. Information Processing and Management, 42, 248-263.

Jones, B .y Goff, M. (2011). Learning to live with data deluge and what that means for educators. En M. J. Hernández Serrano y M. Fuentes Agustí. (Coords.) La red como recurso de información en educación. Revista Teoría de la Educación: Educación y Cultura en la Sociedad de la Información. vol. 12, $\mathrm{n}^{\circ}$ 1. Universidad de Salamanca, pp. 9-27 [Fecha de consulta: 14/02/2013].

http://campus.usal.es/ revistas_trabajo/index.php/revistatesi/article/view/7820/7848

Liaw, S.-S., Chang, W.-C., Hung, W.-H. y Huangb, H.-M. (2006). Attitudes toward search engines as learning assisted tool: approach of Liaw and Huangb's research model. Computers in Human Behaviour, 22, 177-190.

Monereo, C. y Castelló, M. (1997). Las estrategias de aprendizaje: cómo incorporarlas a la práctica educativa. Bacelona: Edebé.

Monereo, C., Fuentes, M. (2005). Aprender a buscar y seleccionar en Internet. En C. Monereo. (Coord.). Internet y competencias básicas. (pp.27-50). Barcelona: Editorial Graó.

Monereo, C., Fuentes, M. y Sánchez, S. (2000). Internet search navigation strategies used by experts and beginners. Interactive Educational Multimedia, 1, 24-34.

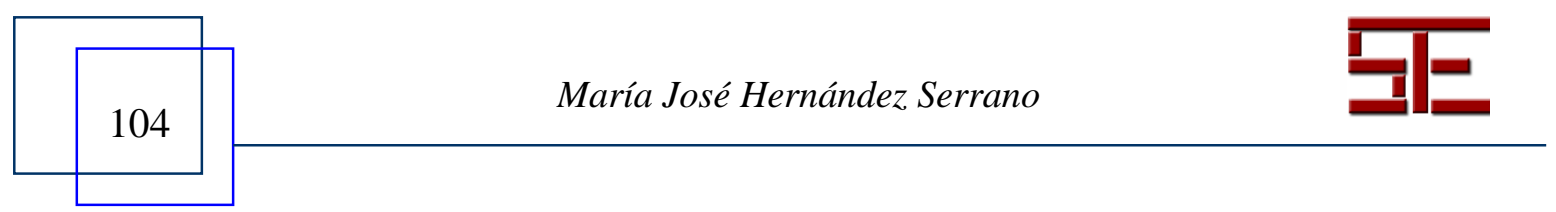




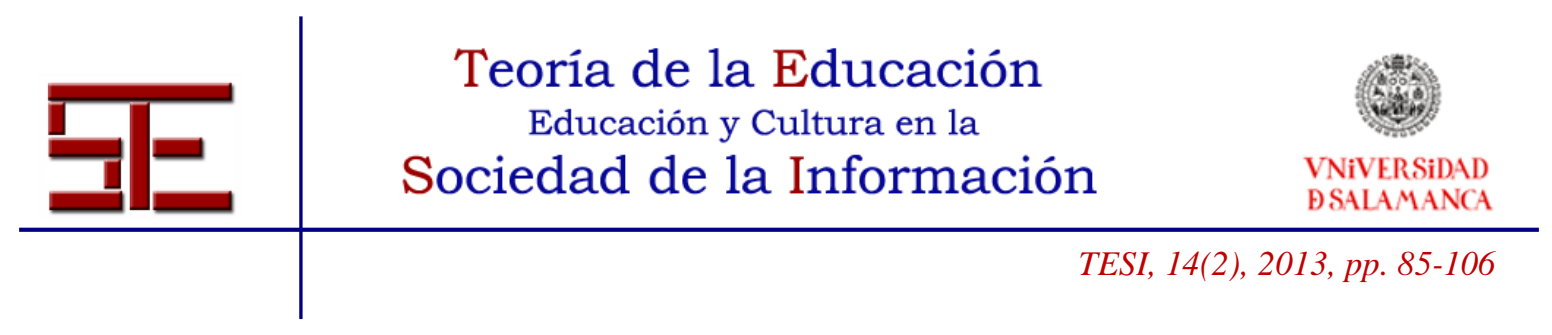

Morin, E. (2001). Los siete saberes necesarios para la educación del futuro. Barcelona: Paidós.

Newman, L. W. (2003). Social Research methods. Qualitative and quantitative approaches. Boston: Allyn and Bacon.

Nisbet, J. D. y Shucksmith, J. (1993). Estrategias de aprendizaje. Madrid: Santillana.

Pharo, N. (2004). A new model of information behaviour based on the search situation transition schema. Information Research, 10 (1).

Salden, R. J. C. M., Pass, F. y Van Merriënboer, J. J. G. (2006). A comparison of approaches to learning task selection in the training of complex cognitive skills. Computers in Human Behavior, 22, 321-333.

Savolainen, R. y Kari, J. (2006). Facing and bridging gaps in Web searching. Information Processing y Management, 42, 519-537.

Tsai, M. (2009). Online information searching strategy inventory (OISSI): A quick version and a complete version. Computers \& Education, 53 (2), 473-483.

Tu, Y., Shih, M., \& Tsai, C. (2008). Eighth graders' web searching strategies and outcomes: The role of task types, web experiences and epistemological beliefs. Computers \& Education, 51(3), 1142-1153.

Winsler, A., Naglieri, J. Y Manfra, L. (2006). Children's search strategies and accompanying verbal and motor strategic behavior: Developmental trends and relations with task performance among children age 5 to 17. Cognitive Development, 21, 232-248.

Xie, I., \& Joo, S. (2010). Transitions in search tactics during the web-based search process. Journal of the American Society for Information Science and Technology, 61(11), 2188-2205.

Yuan, X., \& Belkin, N. J. (2010). Investigating information retrieval support techniques for different information-seeking strategies. Journal of the American Society for Information Science and Technology, 61(8), 1543-1563.

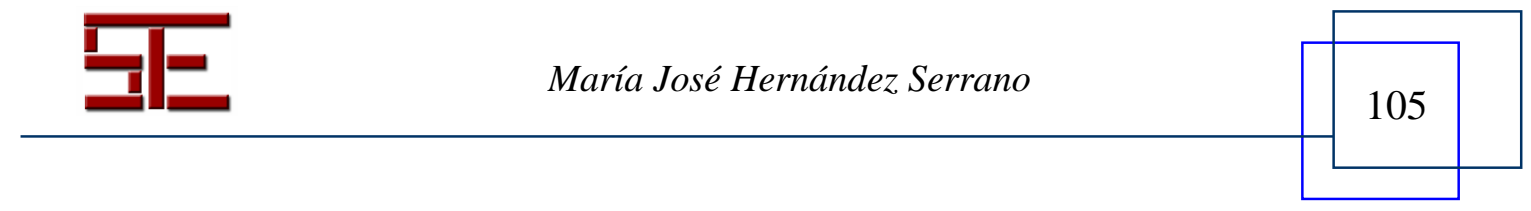




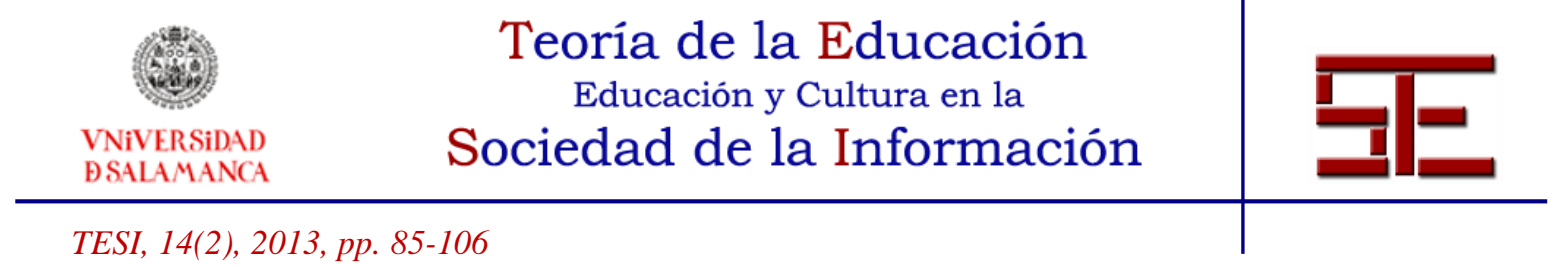

Para citar el presente artículo puede utilizar la siguiente referencia:

Hernández Serrano, M. J. (2013). La búsqueda y selección de la información online: análisis de las acciones estratégicas de los estudiantes universitarios. Revista Teoría de la Educación: Educación y Cultura en la Sociedad de la Información. 14(2), 85-105 [Fecha de consulta: $\mathrm{dd} / \mathrm{mm} / \mathrm{aaaa}]$.

http://campus.usal.es/ revistas_trabajo/index.php/revistatesi/article/view/10214/10624 